\title{
دور التضامن الاجتماعي في إعادة تأهيل العاث الجاتح في ضوء قانون رعاية الأحداث العراقي
}

$$
\text { مازن خلف ناصر }
$$

قسم القانون العام، كلبة القانون، الجامعة المستنصرية، العراق

dr.mazin67@uomustansiriyah.edu.iq الباحث الممثل: مازن خلف ناصر؛ البريد الاككتروني: * استلم في: 30 أكتوبر 2021 / قبل في: 20 نوفمبر 2021 / نشر في: 31 ديسمبر 2021

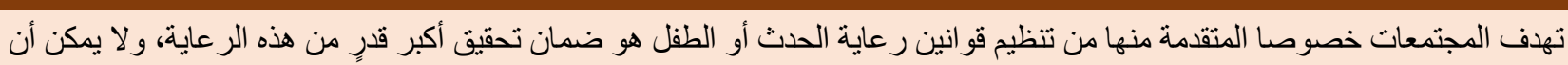

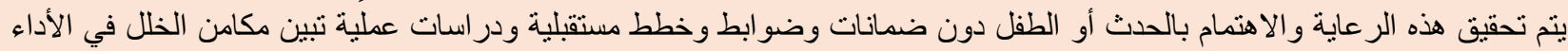

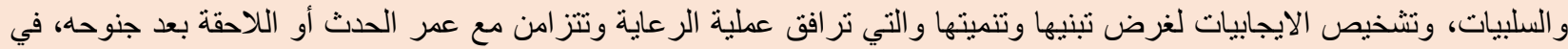

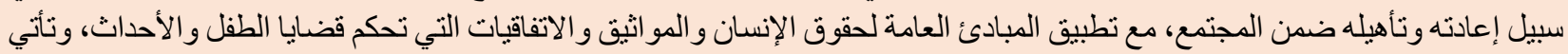

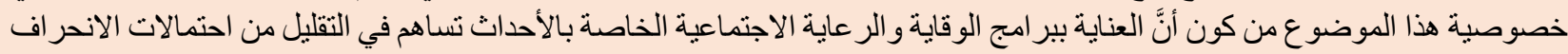

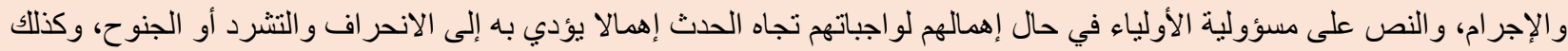

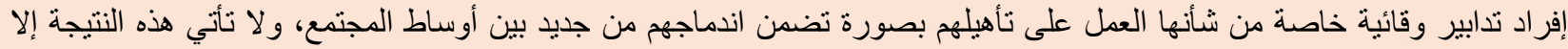

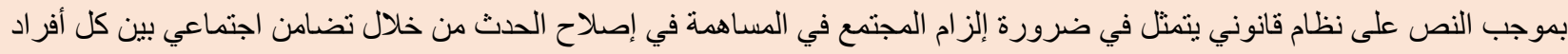

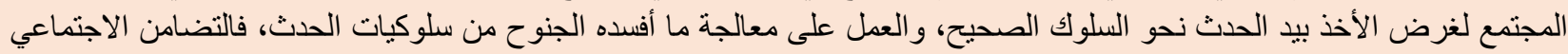

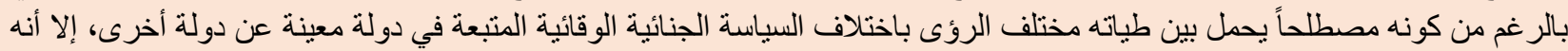

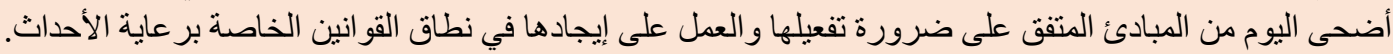

\section{الكلمات المفتاحية: الحدث، الوقاية، التضامن، التأهيل، الانحر اف.}

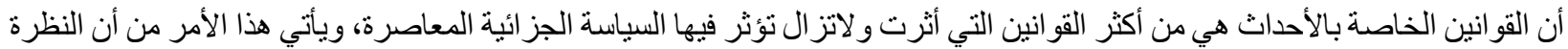

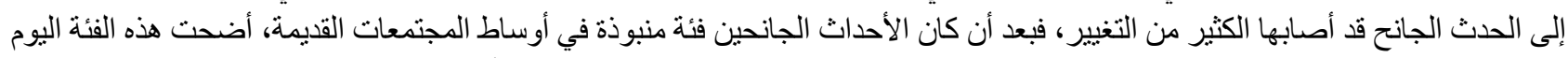

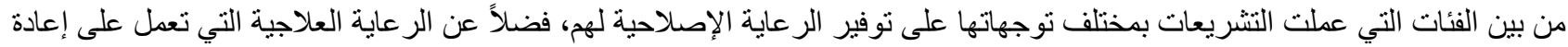

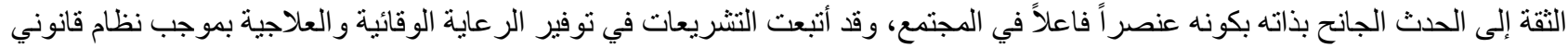

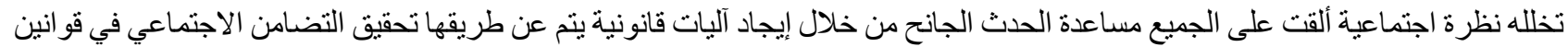
رعاية الأحداث جزئية بحثنا.

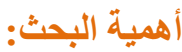

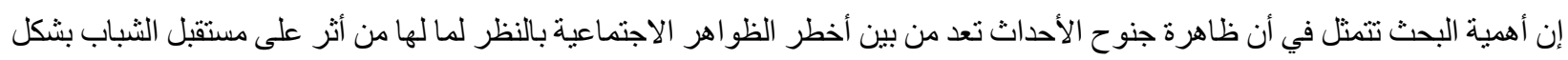

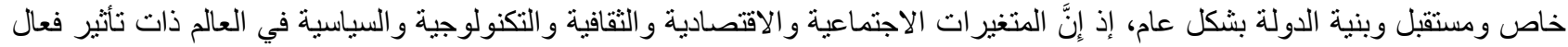

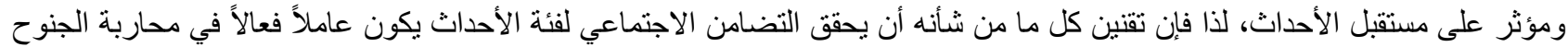

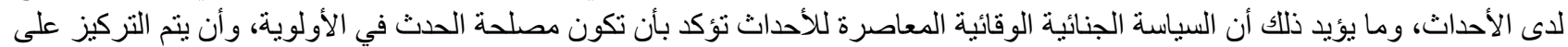

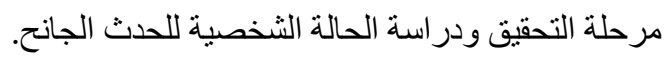

هاف البمن:

لموضو ع بحثنا أهداف متعددة تتجلى في النقاط الأتية: 1- تحديد المفهوم القانوني للتضامن الاجتماعي وتطور السياسة الجنائية الوقائية بشأن إعادة تأهيل الحدث الجانح. 
2- بيان التحديد التشريعي للأحكام الموضوعية في إعادة تأهيل الحدث الجانح وفقا لأحكام قانون رعاية الاحداث العر اقي رقم 76 لسنة

3- تحديد دور الجهات الرسمية وغير الرسمية في تحقيق التضامن الاجتماعي من أجل إعادة تأهيل الحدث الجانح. 4- معرفة الوسائل التي من خلالها يتم تعاون الجهات المختصة لتوفير أفضل السبل لإنجاح خطو اتها نحو إعادة الحدث الجانح الى حضيرة المجتمع كعضو فعال.

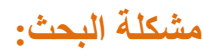

إنَّ إنشكالية دراسة هذا الموضوع تبرز من الجانب النظري في أن العديد من النصوص التي أشار فيها المشرع إلى دور سياسته الوقائية في

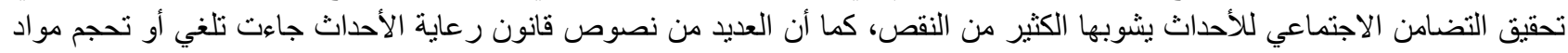

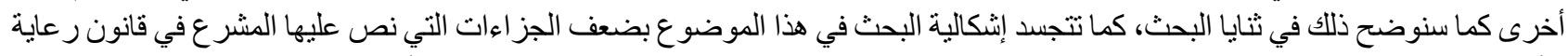

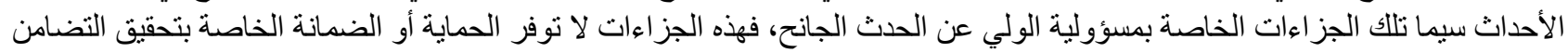

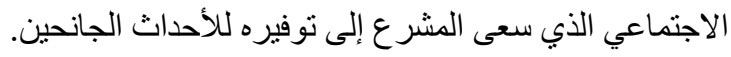

من

من أجل الإحاطة بموضوع البحث من جميع جوانبه يتطلب منا ذلك الاستعانة بالمنهج الاستقرائي للوصول الى نتائج نتفق مع الفكرة المطروحة، بما يتلاعم مع إثكالية البحث، وكذلك ارتأينا الخوض في في غمار المنهج التحليلي لكثف النقص الذي يتخلل التشريع موضوع البحث. بالئ.

ه

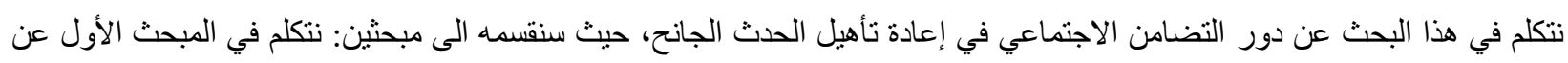
ماهية التضامن الاجتماعي للأحداث، ونخصص المد المبحث الثاني لدور الجهات المجتمعية في تحقيق التضامن الاجتماعي للأحداث.

المبحث الأول

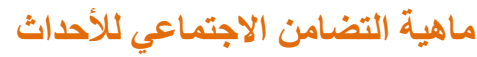

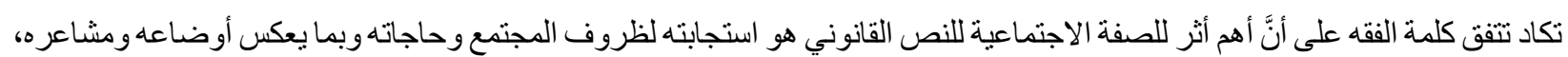
و عدم اقتصاره على زمن نشوئه أو صدوره هذا من ناحية، ومن ناحية أخرى أن هدف تطبيق التهن القانون هو تحقيق العدالة الاجتماعية ولا تتأتى هذه

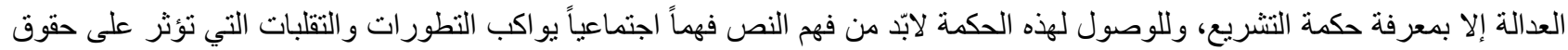

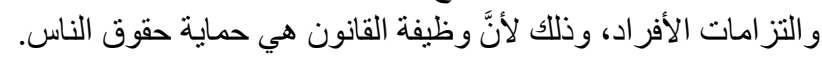
وسوف نحاول في هذا المبحث أن نستعرض التضامن الاجتماعي بوصفه أحد المفاهيم الاجتماعية التي تناولها المشرع العر اقي في قانون

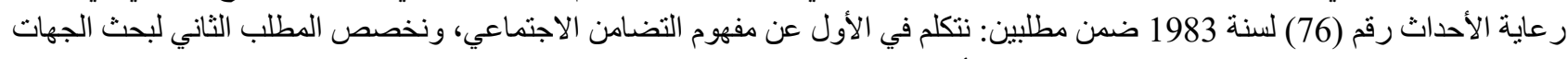

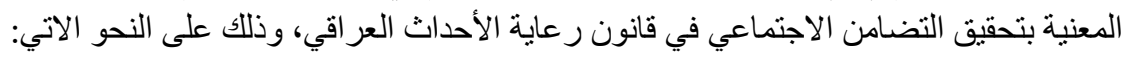

المطلب الأول

مفهوم الثنضامن الإنثماعي

مما لا شك فيه أن لكل دولة تشريعاتها الخاصة التي تعمل من خلالها على تنظيم حياة الأفراد في المجتمع، وذلك لكون أن هذه التشريعات

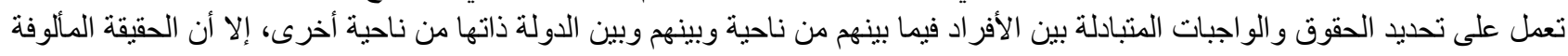

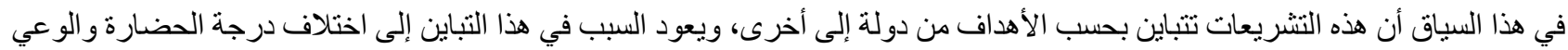

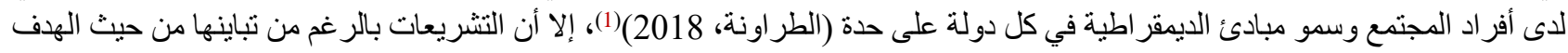
إلا أنها تشترك في أمر النشأة، إذ أن الدول تسلك أحد الطريقين في تنظيم أمر أو مسألة معينة، فأما أن تتبع في سن تشريعاتها الطريقة المكتبية الذانية

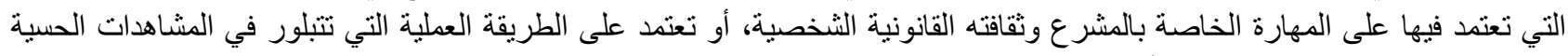

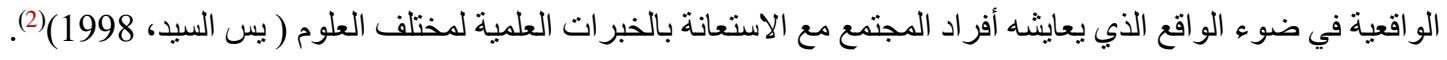




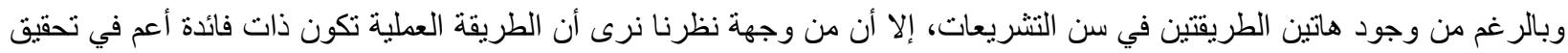

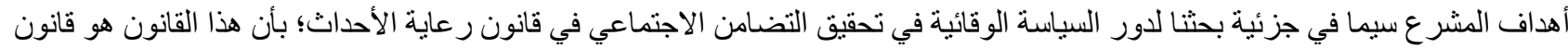
وقائي أكثر من كونه قانون عقابي، وسوف نحاول في هذا المطلب أن نبين معنى التضامن الاجتماعي في فر عين مستقلين وذلك على النياعن النحو الآتي:

الفرع الأول

معنى التضامن الاجتماعي في اللغة و الاصطلاح

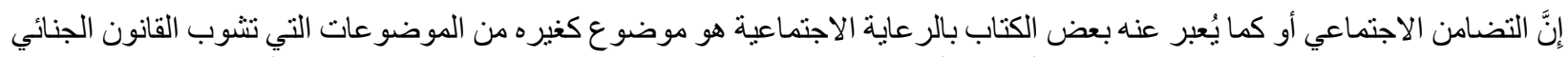

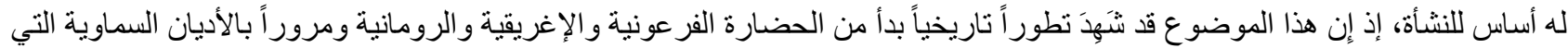

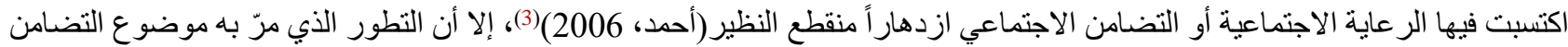

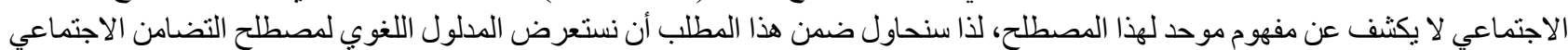
وتعريفه من الوجهة الاصطلاحية ضمن فرعين مستقلين وكالآتي:

أولا: التعريف اللغوي للتضامن الاجتماعي

إنَّ مصطلح التضامن الاجتماعي هو مصطلح مركب من كلمني التضامن والاجتماعي، ولهاتين الكلمتين مدلول لغوي محدد، إذ أن كلمة

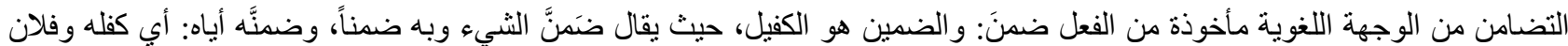

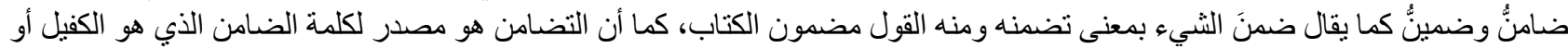

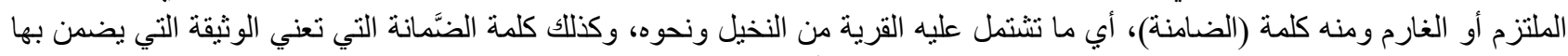

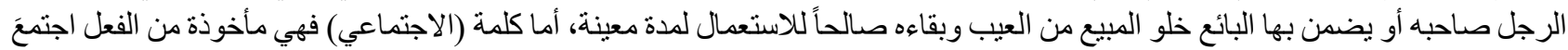

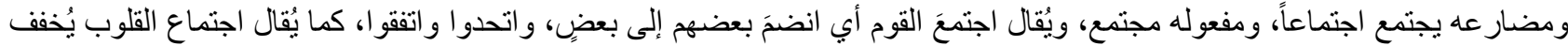

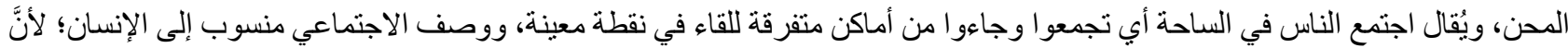
الإنسان اجتماعي بطبعه له فطرة تميل إلى معاثرة الناس في المجتمع و الاختلاط بهم، وكلمة " اجتمع" هي ضد كلمة فئة "تفرقَ" (بعقوب، 1987)(4).

ثُانيا: التعريف الاصطلاحي للتضامن الاجتماعي

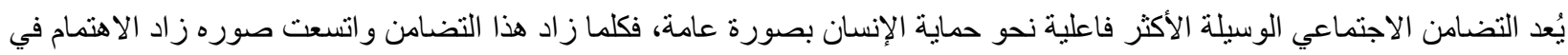

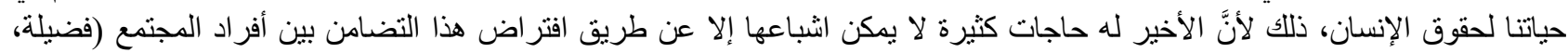

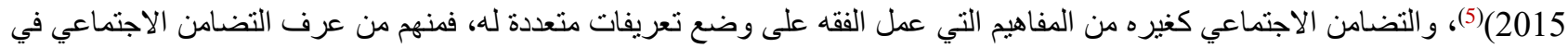

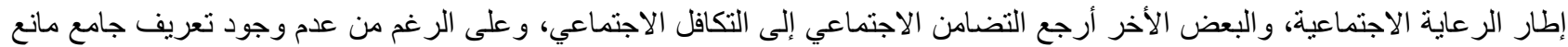

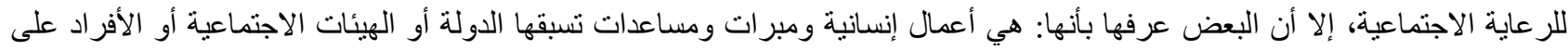

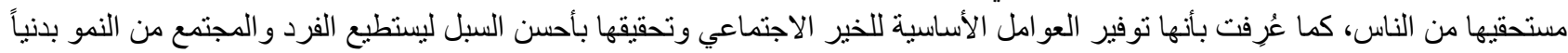

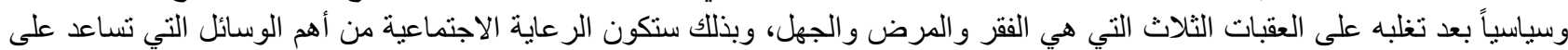

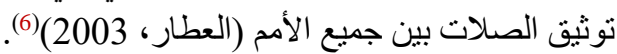

كما عرفت الرعاية الاجتماعية من جانب أخر على أنها: هي نسق منظم من الخدمات والمؤسسات الاجنماعية يرمي إلى مساعدة الأفراد

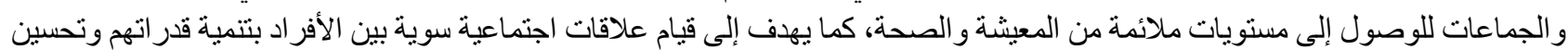

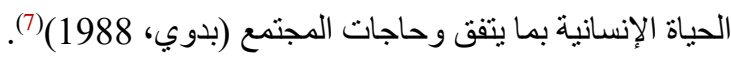

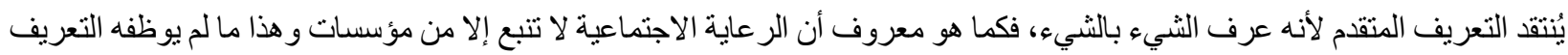

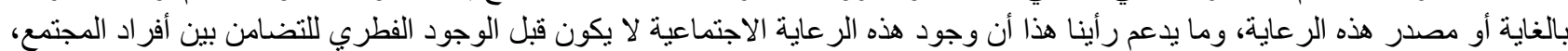

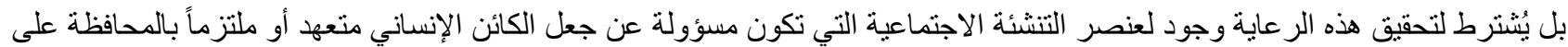
نظامه الاجتماعي باعتباره عضو أ في هذا المجتمع.

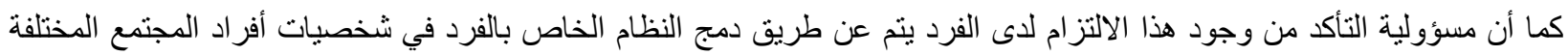

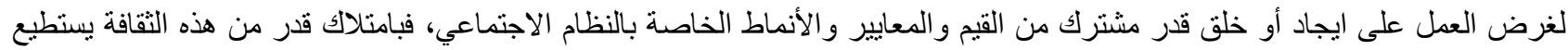

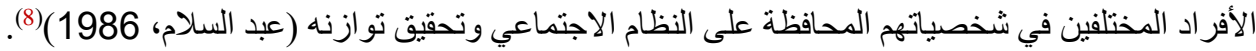

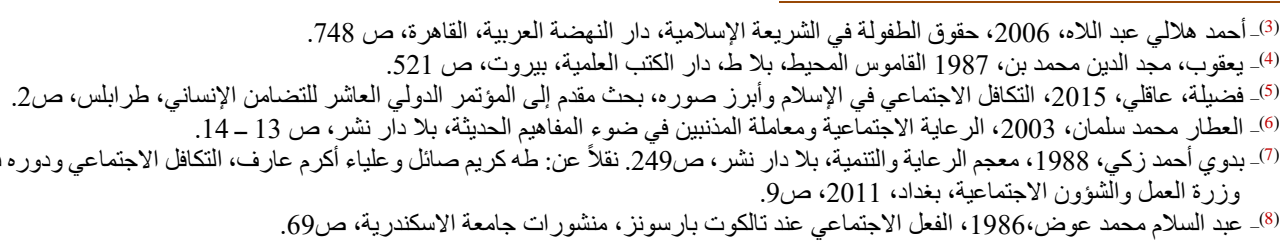


ومن قبيل الاتجاه الذي يرى أن التضامن الاجتماعي هو الرعاية الاجتماعية، يذهب اتجاه أخر إلى تبني فكرة التكافل الاجتماعي كونها تضامناً

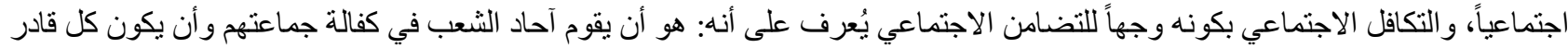

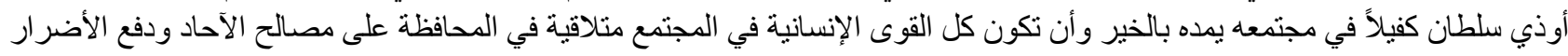

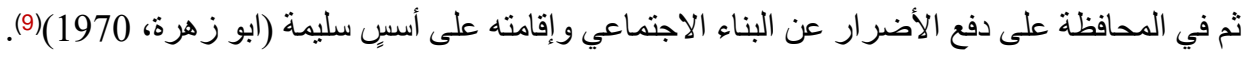

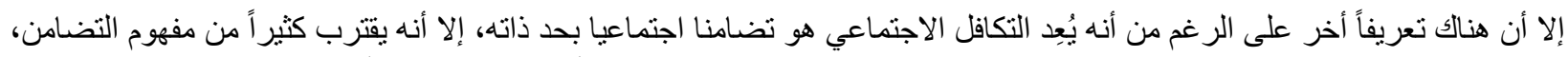

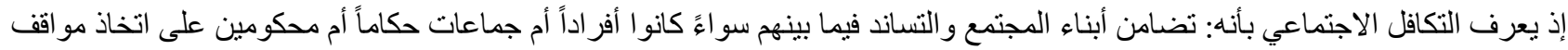
ايجابية كر عاية اليتيم أو سلبية كتحريم الاحتكار بدافع من شعور وجداني عميق ينبع من أمل العقيدة الإسلامية ليعيش الفرد في كفالة الجماعة التيات التيات

$$
\text { وتعيش الجماعة بمؤازرة الفرد حيث يتعاون الجميع ويتضامنون لإيجاد المجتمع الأفضل ودفع الضرر عن أفراده. }
$$

وبالرغم من الجنبة الإيجابية التي أكدها التعريف السابق في إطار ايضاحه لمفهوم التكافل الاجتماعي، إلا أنه يُنتقد من جهة اعتباره السلوك

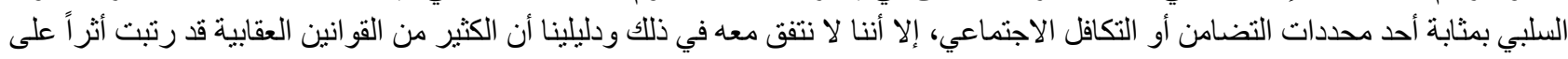

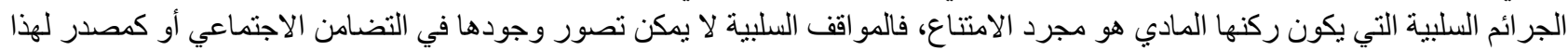
التضامن.

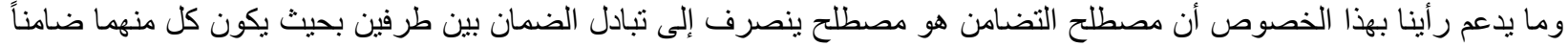

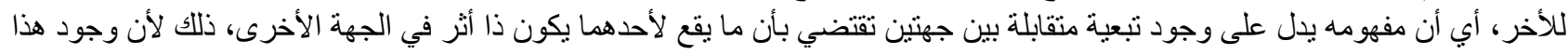

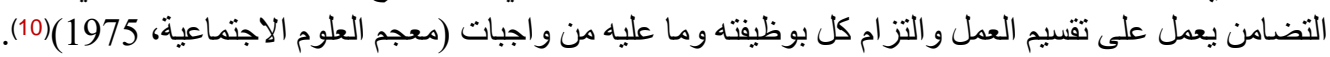
كما عُرف التضامن الاجتماعي في الفقه الغربي على أن: التضامن في جوهره هو الثعور بالتعاطف المتبادل والمسؤولية بين أعضاء المجموعة التي تعزز الدعم المتبادل (11) LAWRENCE (WILDE,2006.

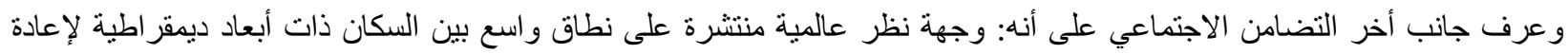

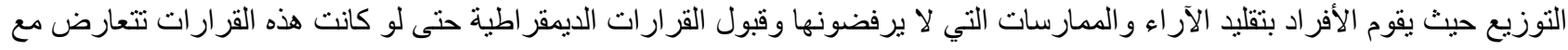

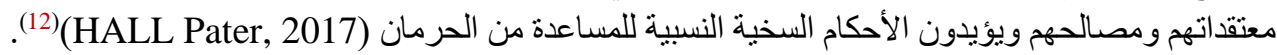

ومن الجدير بالذكر أن فلسفة التضامن الاجتماعي في نطاق قانون رعاية الأحداث تتمثل في وضع مجموعة من التدابير والتي تتمثل في

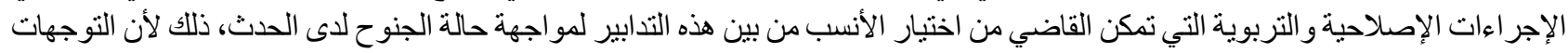

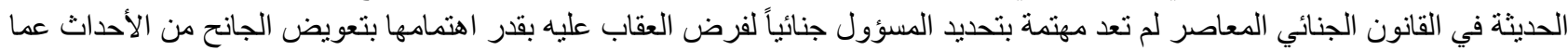
فقده من رعاية كانت سبباً في افساده وتو جيهه الخاطئ و انتهاجه لطريق الجنوح (الثاذلي، 1998) (13).

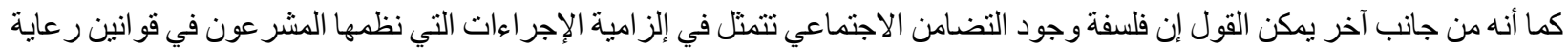

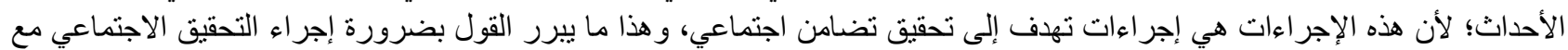

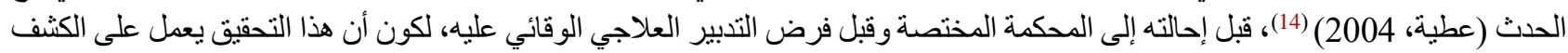

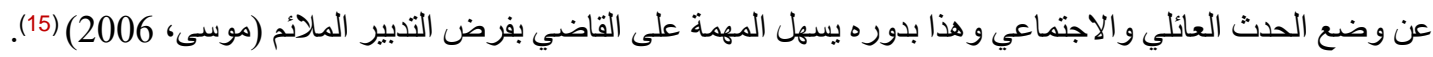

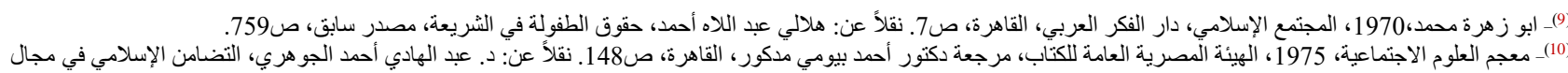

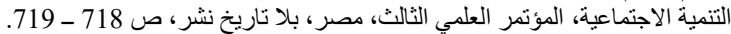

11 LAWRENCE WILDE, the concept of solidarity, Cambridge university,2006, p.1.

12 HALL Pater, the political sources of social solidarity, Harvard library, 2017, p. 349.

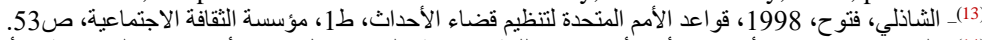

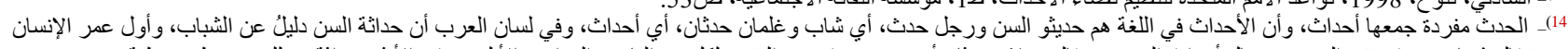

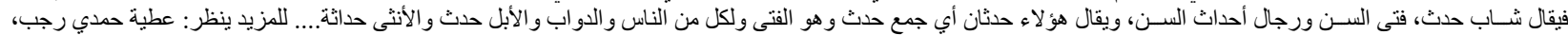

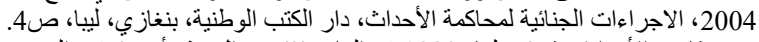

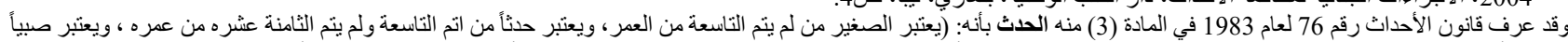

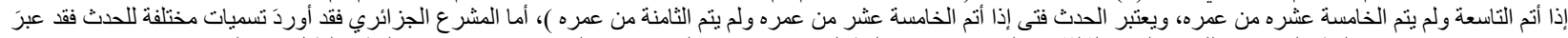

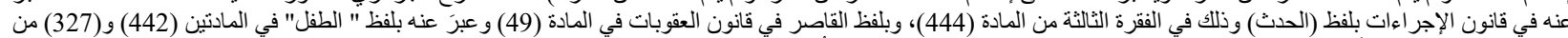

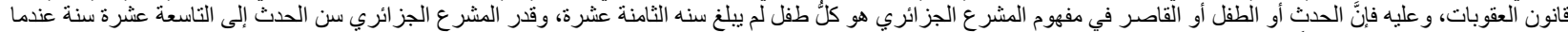

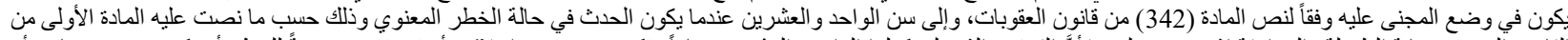

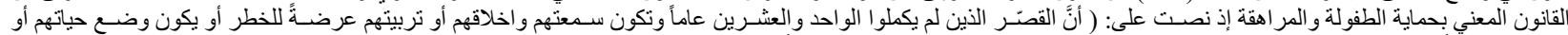

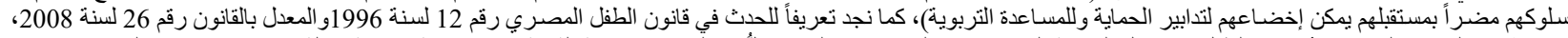

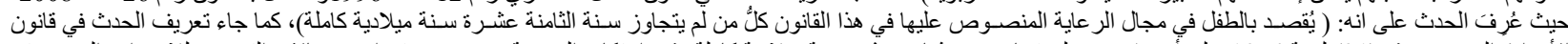

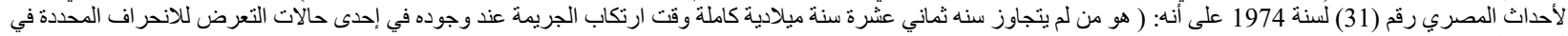

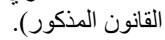

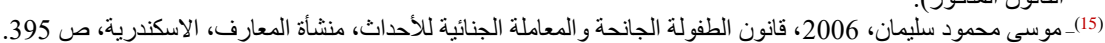




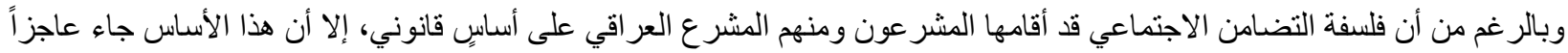

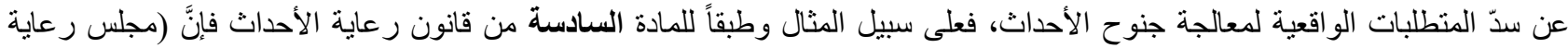
الأحداث) يختص بتقرير الأهداف العامة ووضع الخطط والسياسات التي تكفل التناسق و التكامل في رعاية الأحداث وحمايتهم من الجنوح.

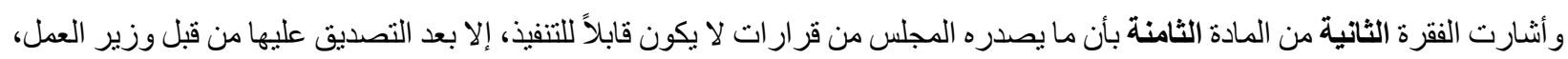

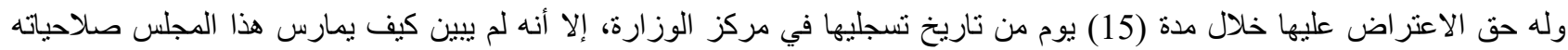

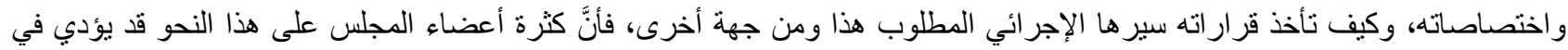

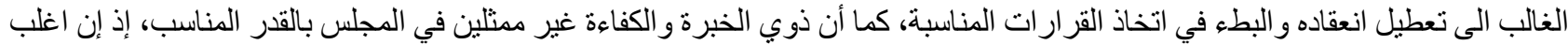

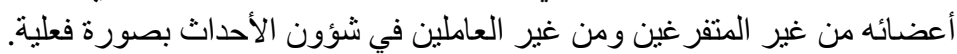

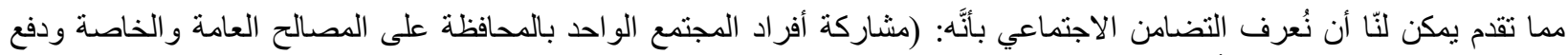

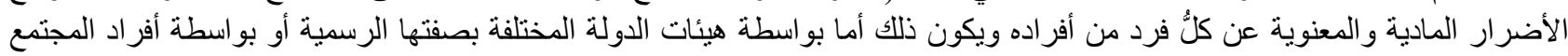

بصفتهم الثخصية).

\section{المطلب الثاني \\ الجهات المجتمعية المعنية بتحقيق التضامن الاجنماعي للحدث الجانح}

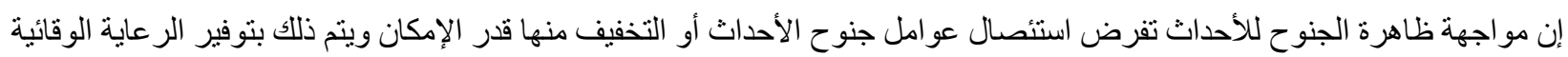

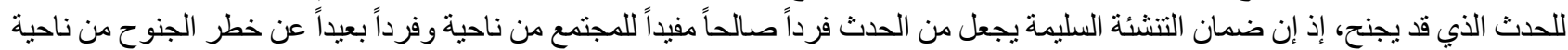

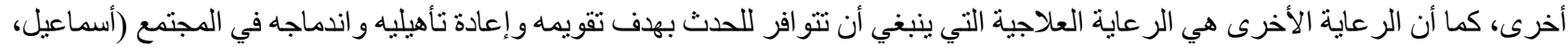

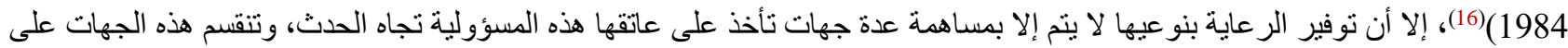
نو عين، سنحاول بيانهما ضمن فر عين مستقلين كالآتي:

الفرع الأول

الجهات الرسمية

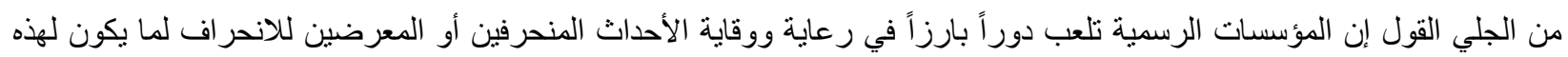

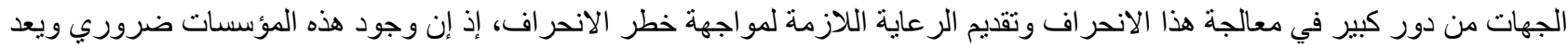

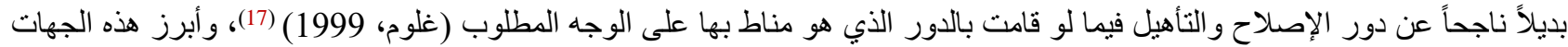
هي:

أولا: شرطة الأحداث

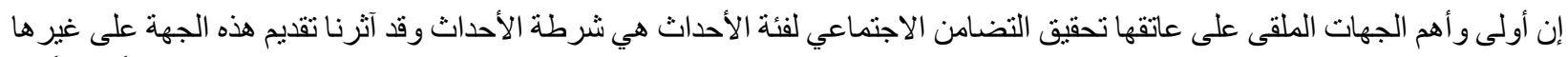

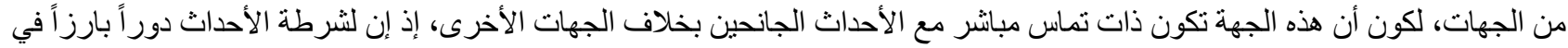

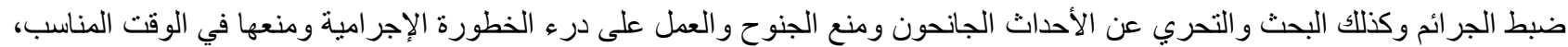

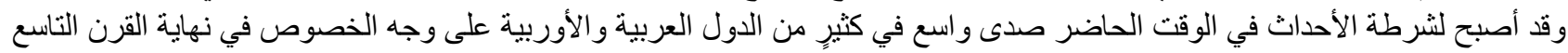

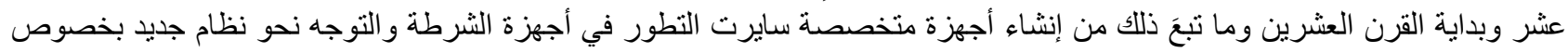

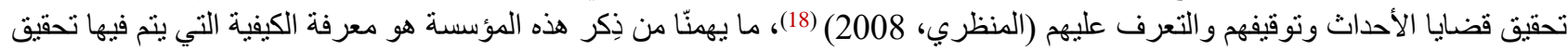

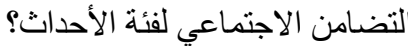

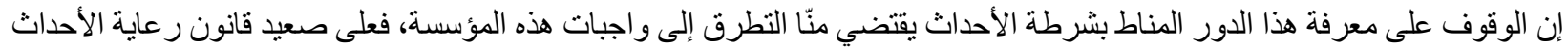

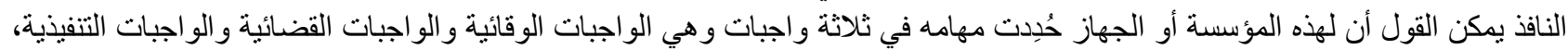

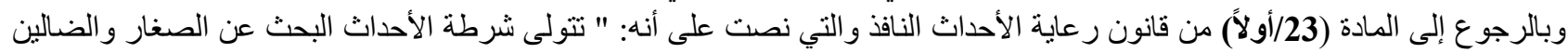

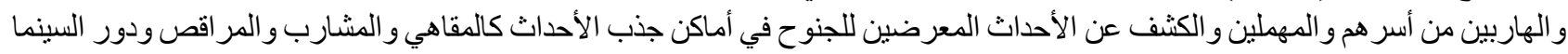
في ساعات متأخرة من الليل".

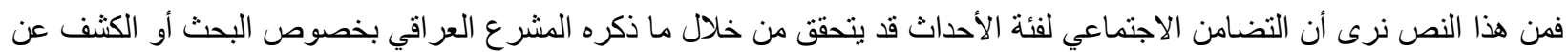

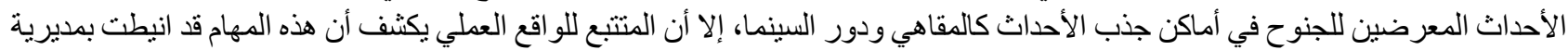

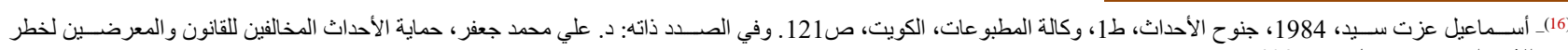

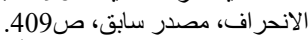

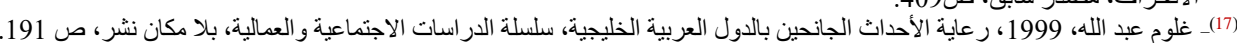

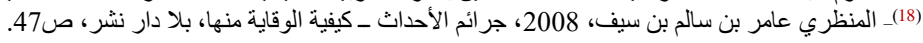


الثرطة السياحية (عنوز، 2015) (19)، بموجب كتاب مديرية الثرطة العامة ذي العدد (11696) لعام 1993 وهذا أمر مخالف وغير جائز، ذللك لأن هذه المهام هي من عمل شرطة الأحداث بموجب قرار مجلس قيادة الثورة (المنحل) رقم 55لسنة 1987 الذي لا يزال ساري النفاذ

(الياسين، 1994) (20).

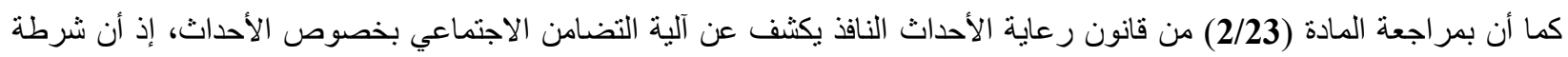

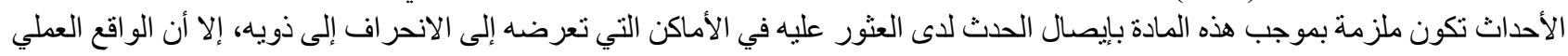

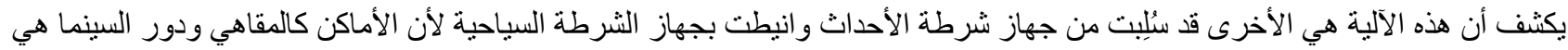
خاضعة لرقابة جهاز الثرطة السياحية (الياسين، مرجع سابق) (21).

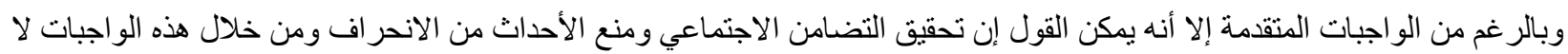
يعد كافيا، إذ أن هناك رأي يذهب إلى أن التضامن الاجتماعي للأحداث يمكن أن ينحقق بموجب التهن آليات أخرى ومنها (مصيلحي، 2009) (22):1- إثغال الأحداث في وقت الفراغ بأعمال مفيدة واستثماره بطريقة سليمة، الأمر الذي يعمل على تخليصهم من الاضطر ابات النفسية.

$$
\text { 2- تدريب الأحداث على حب النظام و التحلي به و العمل على تعميقه في نفوسهم وسلوكهم اليومي. }
$$

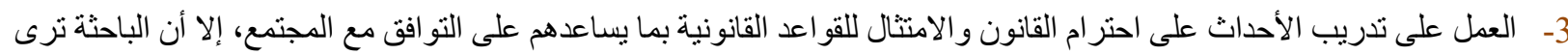

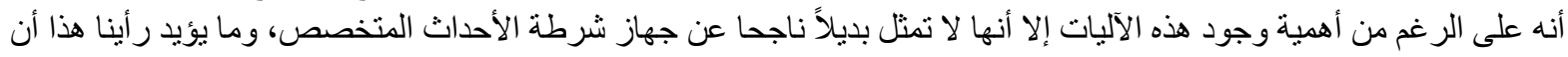

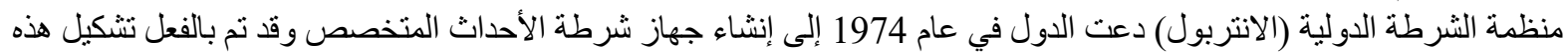

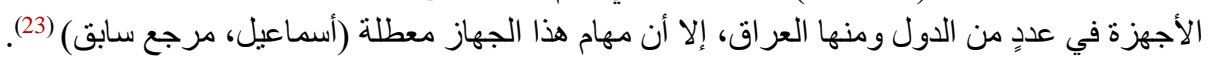

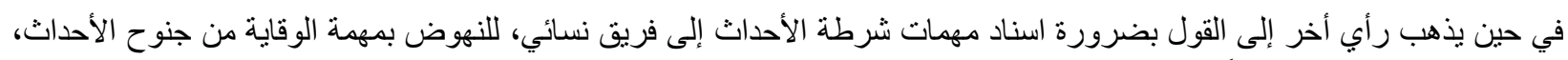

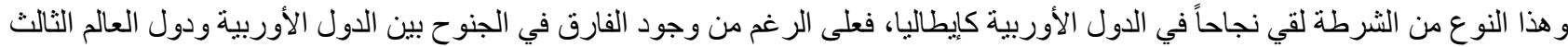

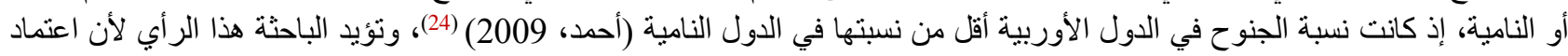

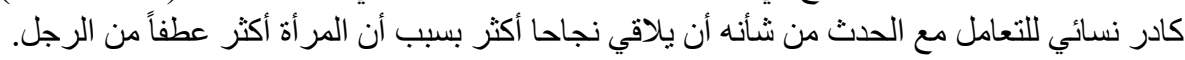

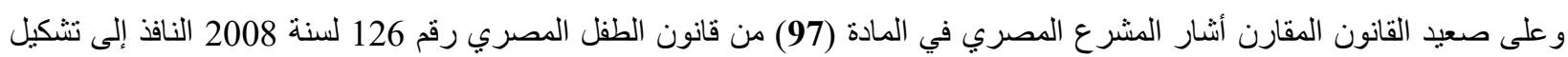

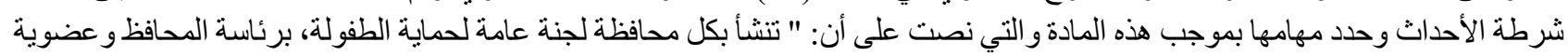

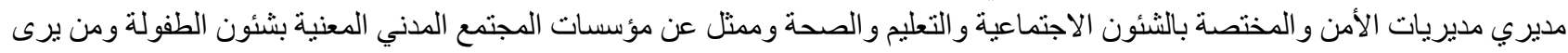

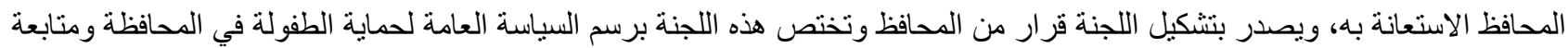

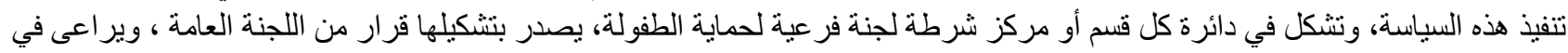

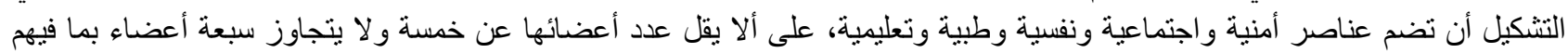
الرئيس، ويجوز أن تضم اللجنة بين أعضائها ممثلا أو أكثر لمؤسيسات المجنمع المئية المدني المعنية بشئون الطفولة. وتختص لجان حماية الطفولة الفرعية بمهمة رصد جميع حالات التعرض للخطر و التنخل الوقائي والعلاجي اللازم لجميع هذه الحالات ومتابعة ما يتخذ من إجر اءات اتلعان.

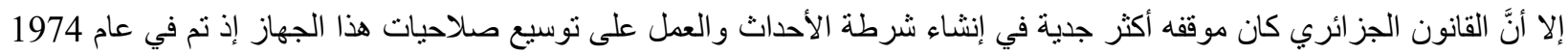

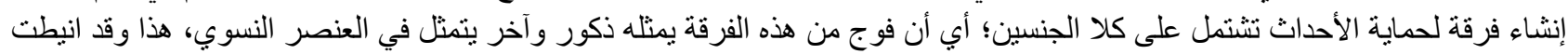

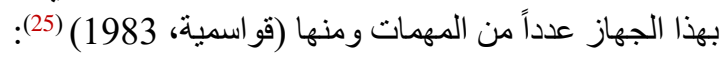

$$
\begin{aligned}
& \text { 1- - مر اقبة الأحداث في المحلات العامة. } \\
& \text { 2- البحث عن الأحداث الضالين و المشردين. } \\
& \text { 3- ضبط الأشخاص الذين يستغلون ضعف أو نزوات الثباب. } \\
& \text { 4- تطبيق التشريعات المتعلقة بحماية الطفولة و المر اهقة وجنوح الأحداث. }
\end{aligned}
$$

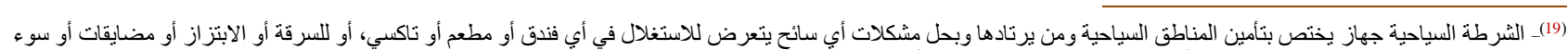

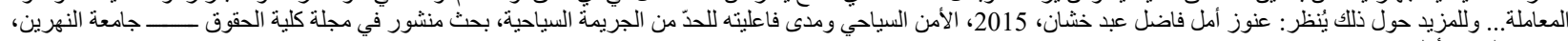

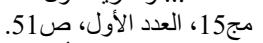

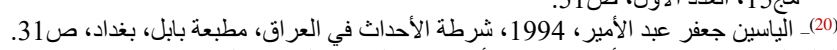

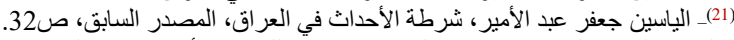

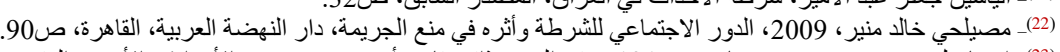

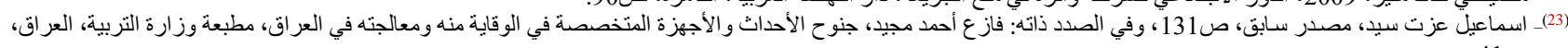

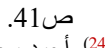

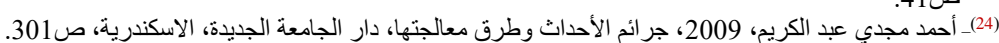

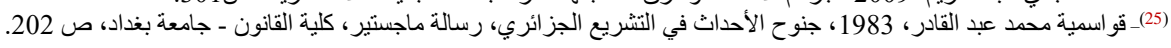




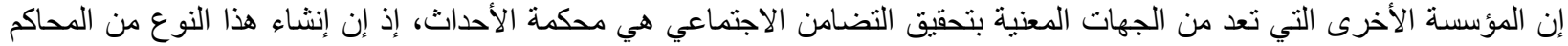

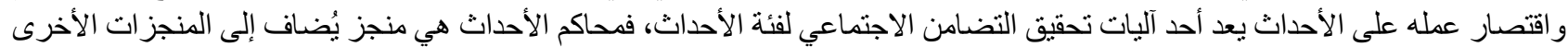

التي كرسنها السياسة الجنائية في الوقت الحاضر بفضل المعطيات التي جاءت بها العلوم الجنائية والإنسانية الحديثة (العبيدي، 1988) (26).

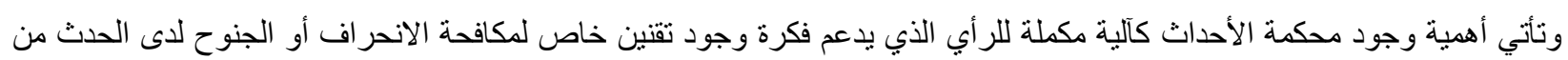

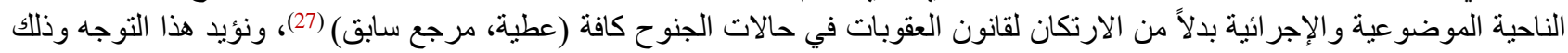

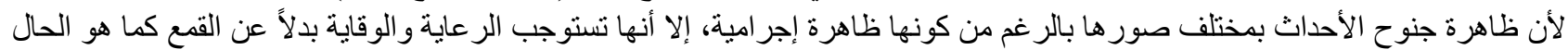
في الظاهرة الإجر امية بصورة عالأنة.

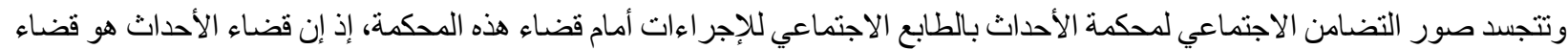

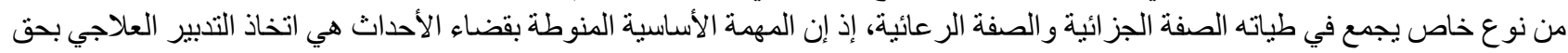

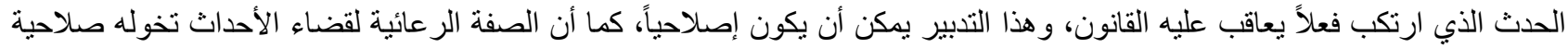

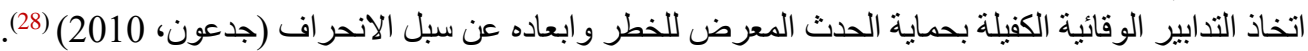

ومن ناحية أخرى يمكن أن نألف وجود التضامن الاجتماعي لمحكمة الأحداث من أن هذه المحكمة لا تقتصر صلاحيتها على رؤية القضايا

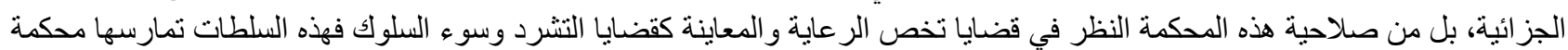

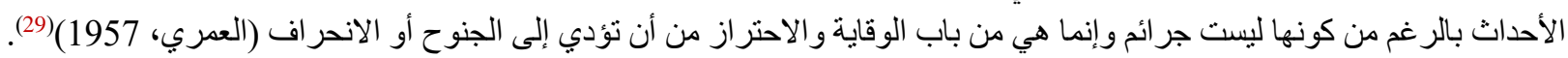

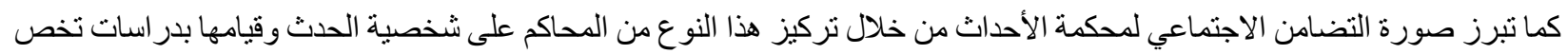

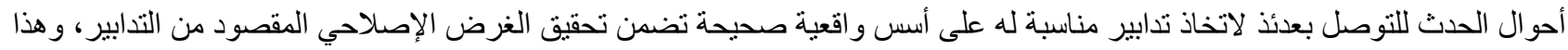

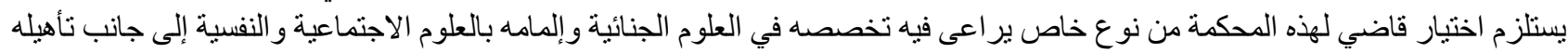

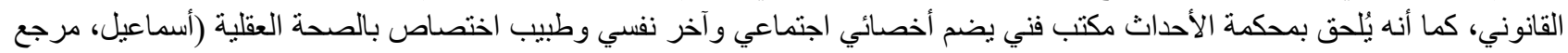
سابق) (30).

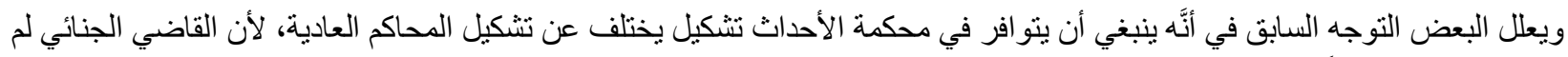

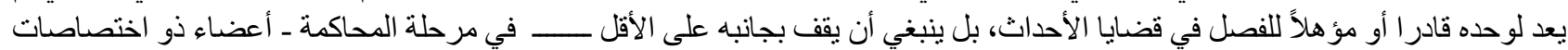

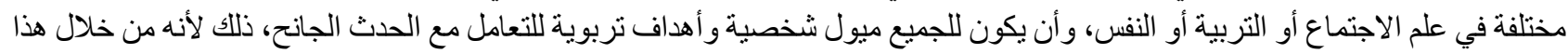

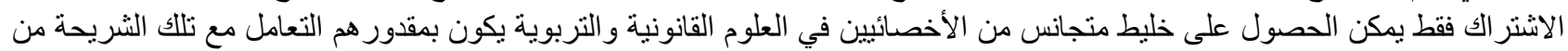

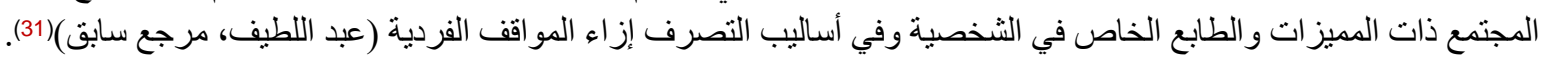

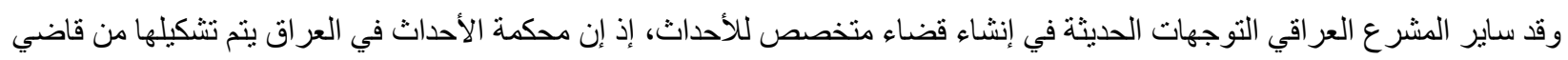

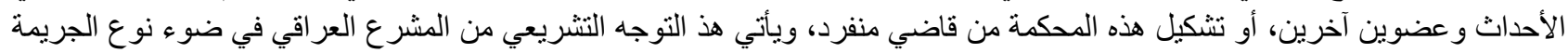

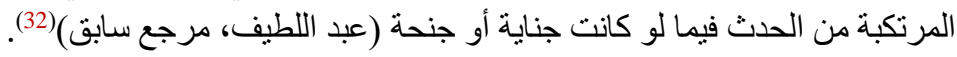

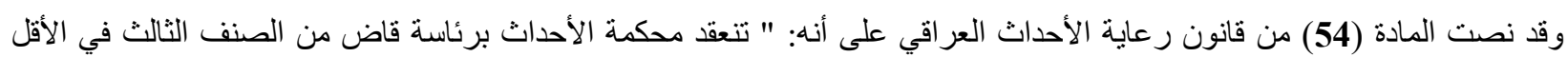

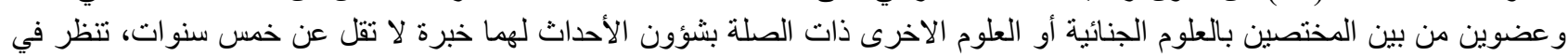

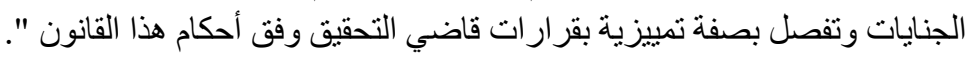

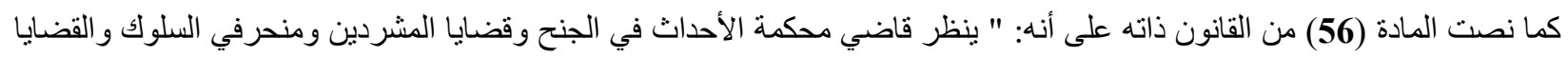

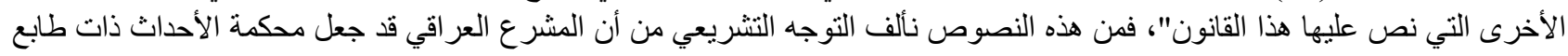

وبالر غم من المو اكبة التشريعية في العر اق للسياسة الجنائية الحديثة، إلا أن البعض ينتقد موقف المشرع العر اقي و اقتصاره في صفة قاضي الكيا

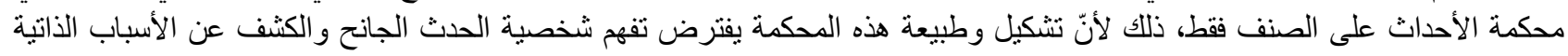

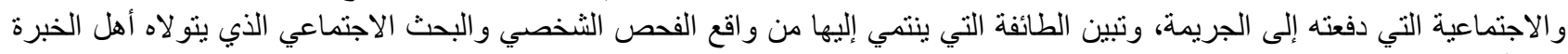

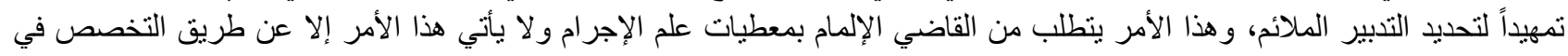

(26)ـ العبيدي عو اد حسين ياسين، 1988، شرح أحكام قانون رعاية الأحداث رقم 76 لسنة 1983، بيت الحكمة، بغداد، ص 135.

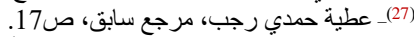

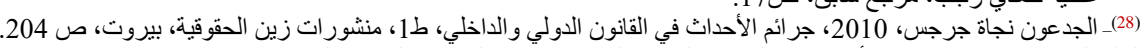

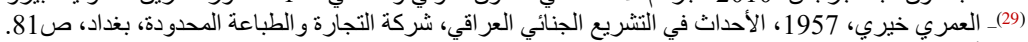

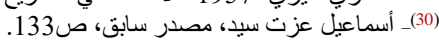

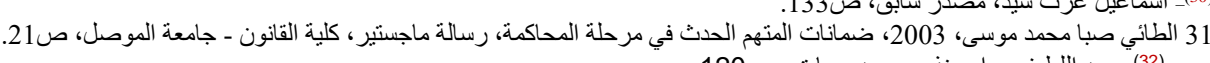
(32)- عبد اللطيف براء منذر، مصدر سابق، ص120. 
المسائل الجنائية (العبيدي، مرجع سابق) و (المختار، 1981) (33)، ومن وجهة نظرنا تؤيد هذا التوجه بداعي أن التخصص يكون له دور كبير في فرض التنبير المناسب لحالة الجنوح التي يقترفها الحدث.

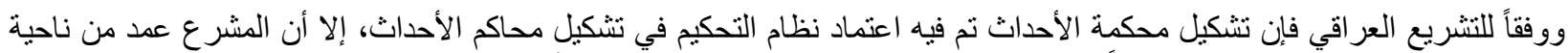

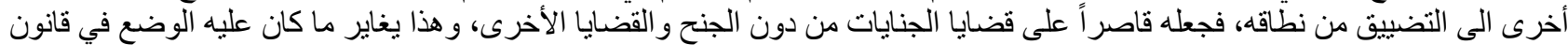

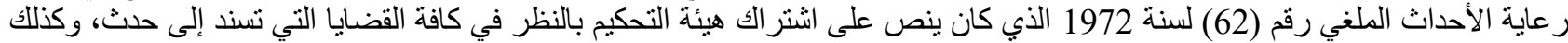

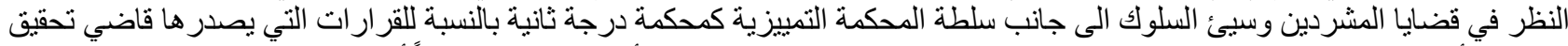

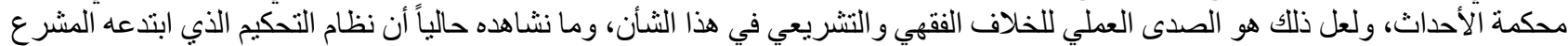

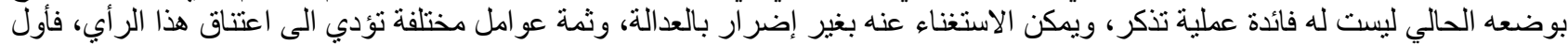
ما يستر عي الآنتباه هو شذوذ وضعه البان البالغ.

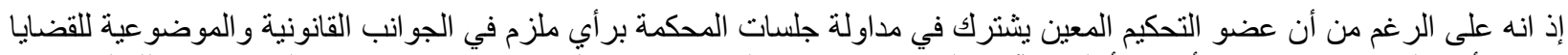

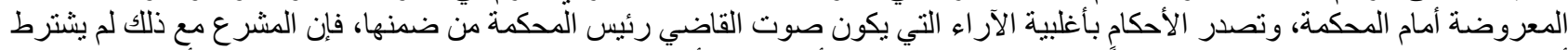

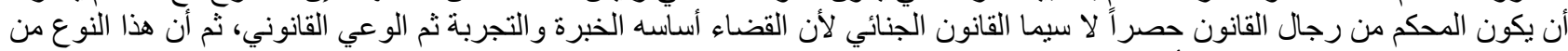

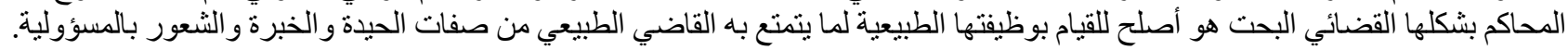

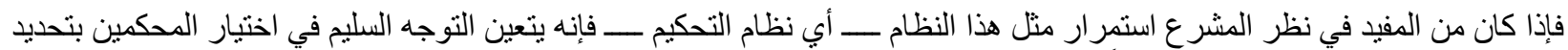

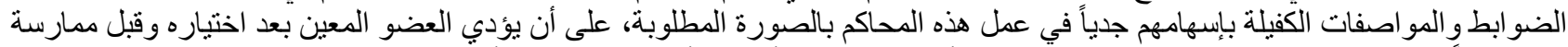

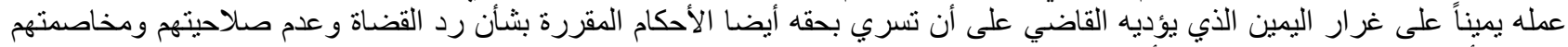

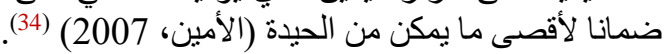

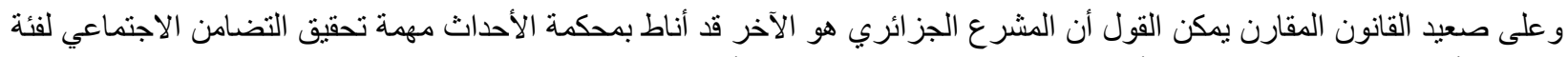

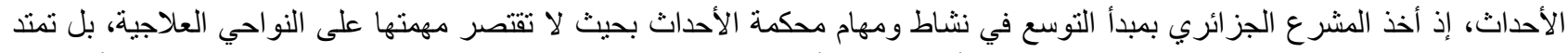

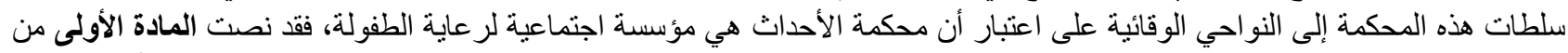

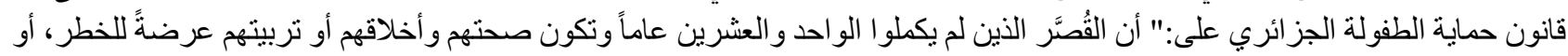

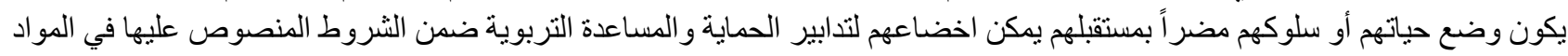

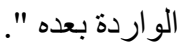

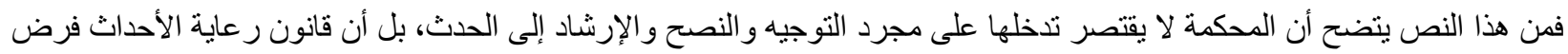

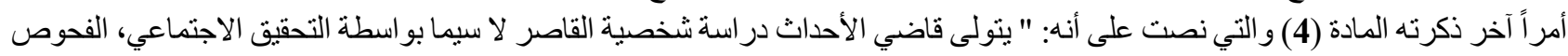

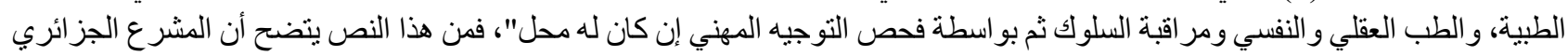

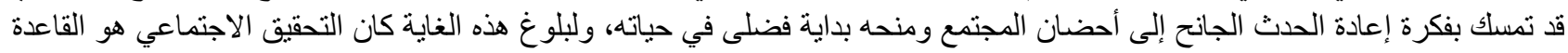
الأساسية لدر اسة أعمق لشخصية الحدث (قو اسمية، مرجع سابق) (35).

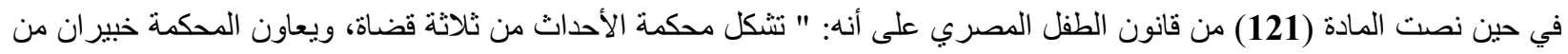

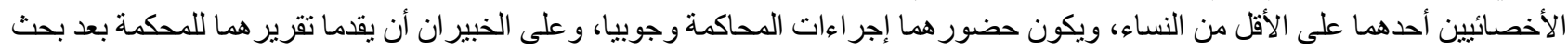

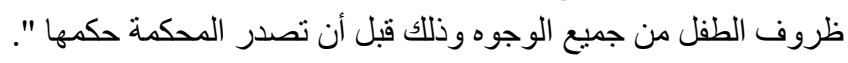

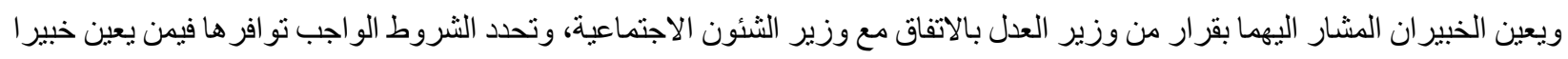
بقرار من وزير الشئون الاجتماعية.

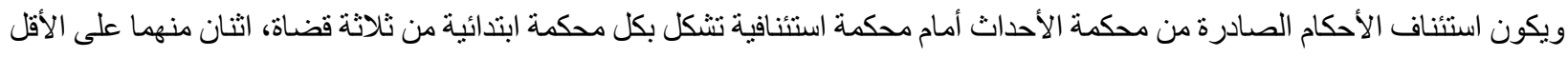

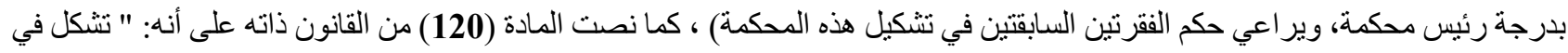

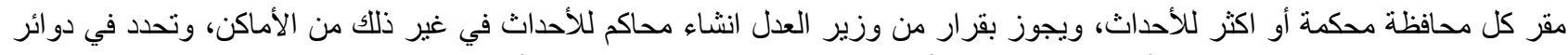

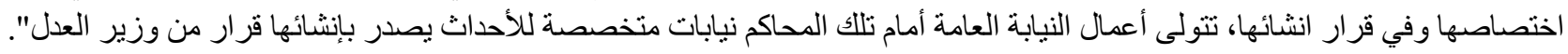

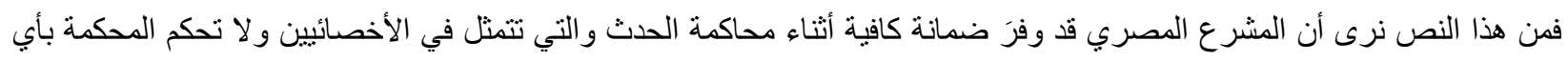

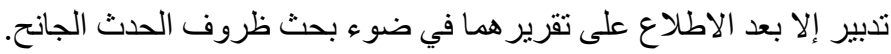

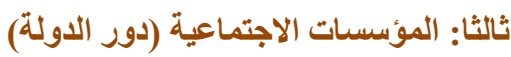

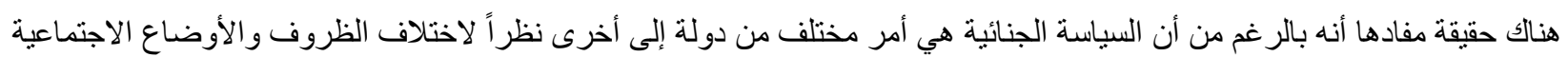

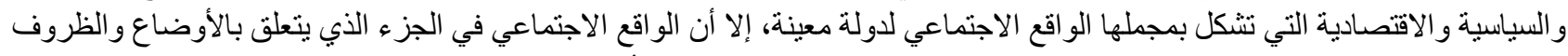

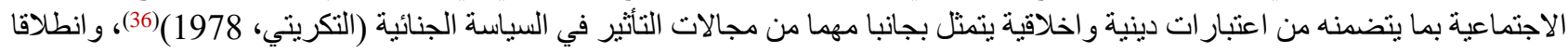

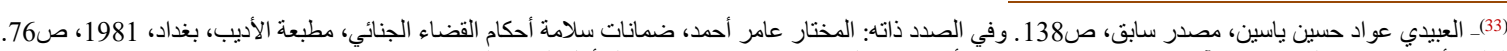

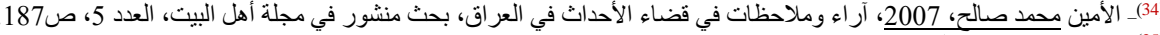

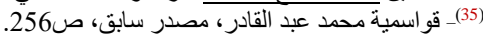
(36) التكريتي منذر كمال عبد اللطيف، 1978، السياسة الجنائية في قانون العقوبات العر اقي، ط1، دار الرسالة للطباعة، بغداد، ص155. 
من الحقيقة الماتلة فإن المؤسسات الاجتماعية يكون عليها عبء في تحقيق التضامن الاجتماعي الخاص بفئة الأحداث أو ما يطلق عليها بـ (دور

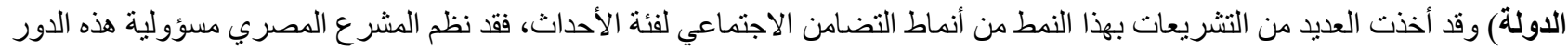

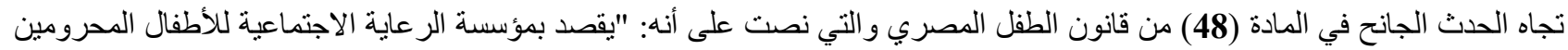

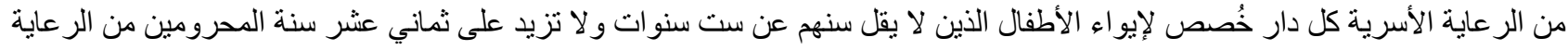

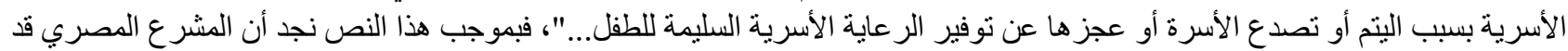

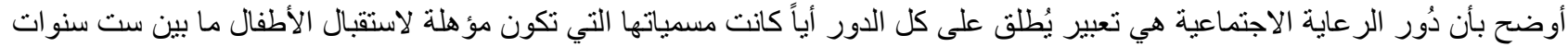

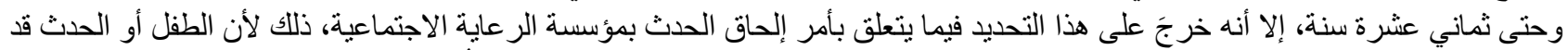

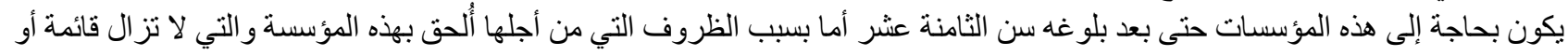

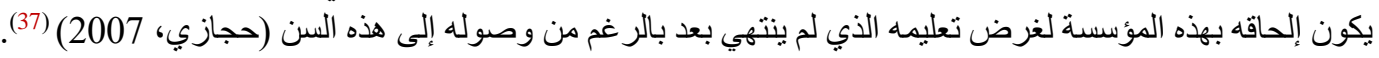

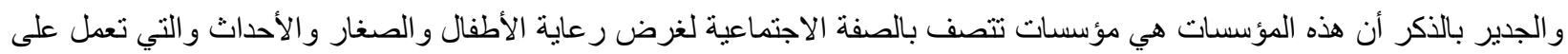

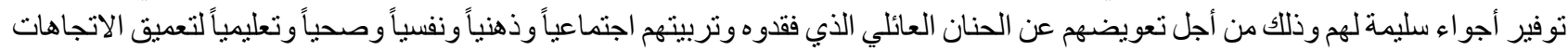

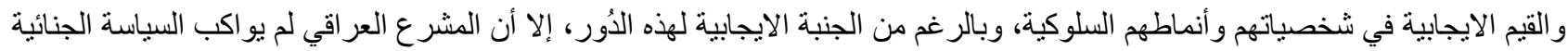

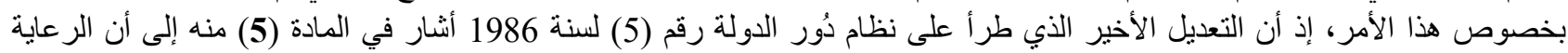

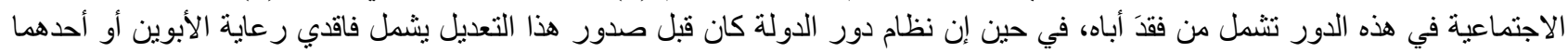

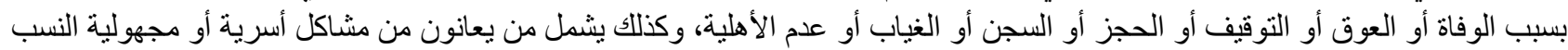

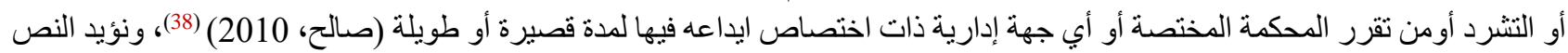
قبل تعديله لما يحققه من ضمانة للحدث الجانح بخلاف النص النافذ حالياً. رابعا: المدرسة

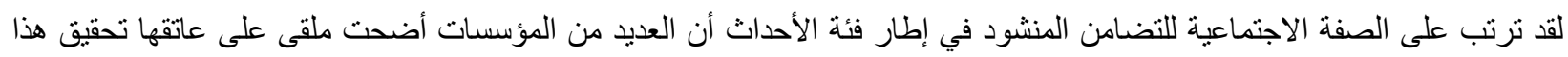

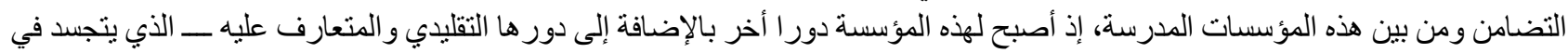

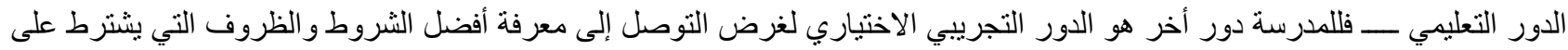

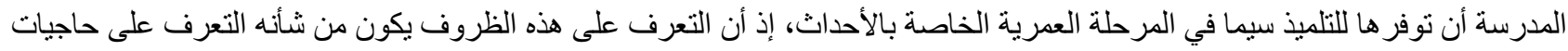

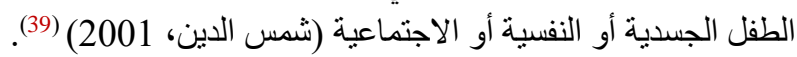

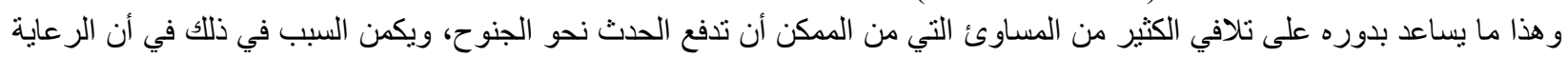

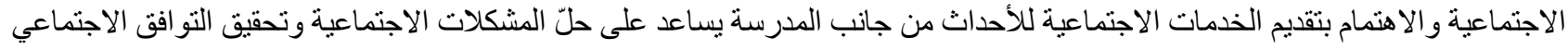
(بوسف، 2006) (400)

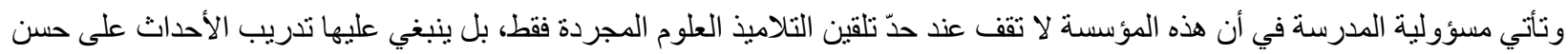

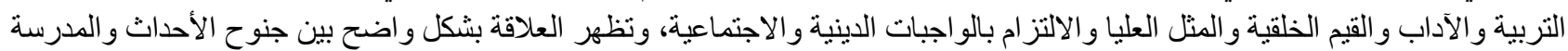

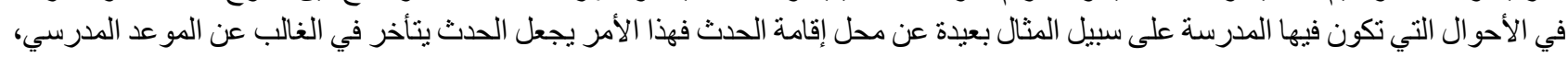

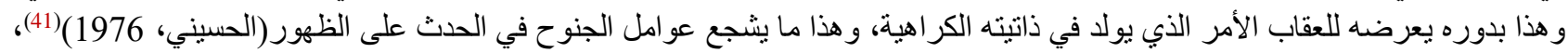

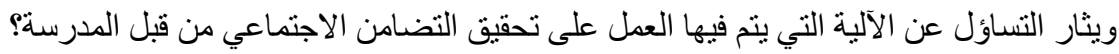

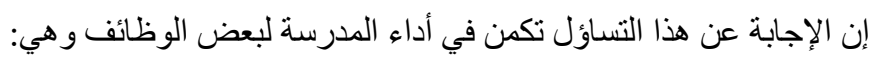
1- محو أثر بعض العادات والسلوكيات غير السليمة التي يكتسبها الحدث من محيطه، و العمل على إزالة ما يتعلق بنفسية الحدث من صر اعات عن طريق الأنشطة التربوية.

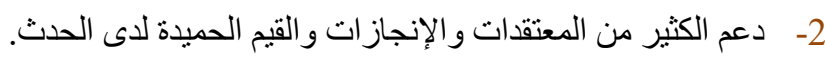
3- تعليم الحدث طرق التفاعل الايجابي مع الغير وتكوين علاقات اجتماعية سوية مع الآخرين (العرود، 2010) (42). 


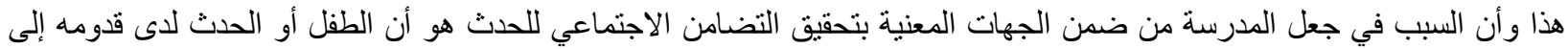

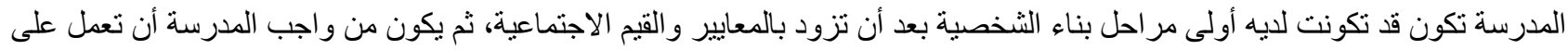

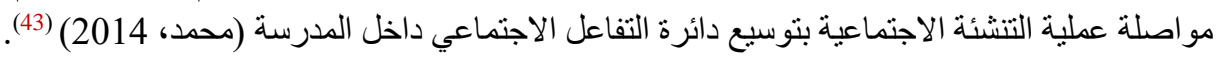
القرع الثناني الجهات غير الرسمية إن تحقيق التضامن الاجتماعي لا يكون مر هوناً بالجهات الرسمية التي ترتبط بثكل أو بأخر بالدولة، بل أن هذا التضامن تساهم به كذلك جهات غير رسمية في تحقيقه، ومن هذه الجهات: أولا: منظمات المجتمع المدني

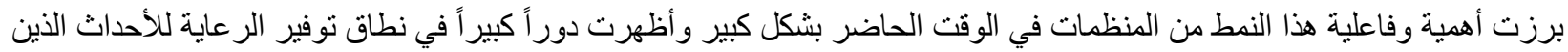

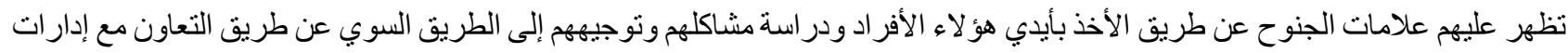

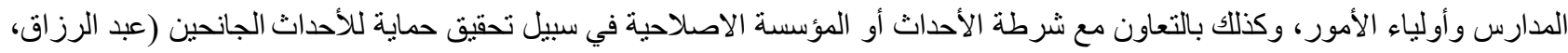
. $^{(44)}(1981$

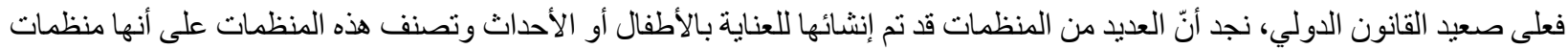

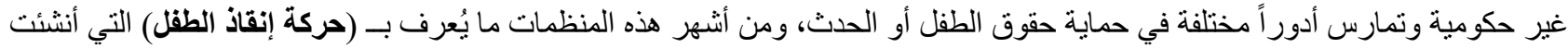

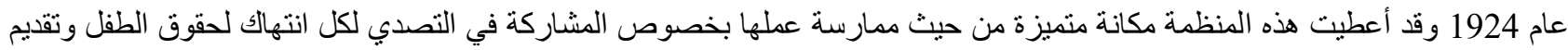

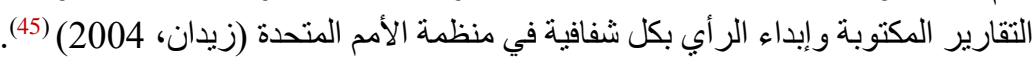

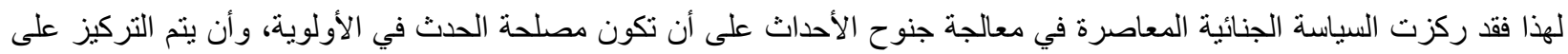

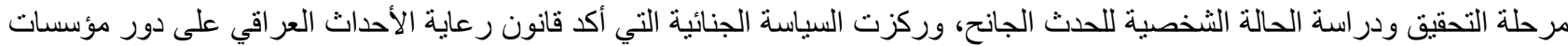

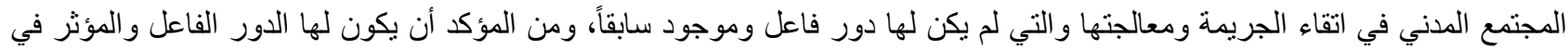

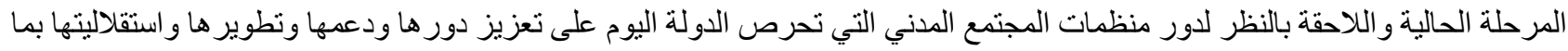

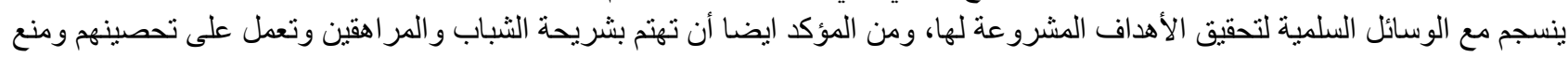
جنوحهم، مع التأكيد كذلك على الدور الإنساني و الاجتماعي لأجهزة العدالة الجنائية الخاصة بالأحداث سواء التهاء منها في مرحلة التحقيق أو المحاكمة أو المرحلة التي تلي الجانب العلاجي و الرعاية اللاحقة للحدث.

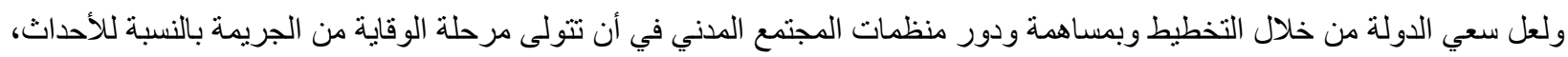

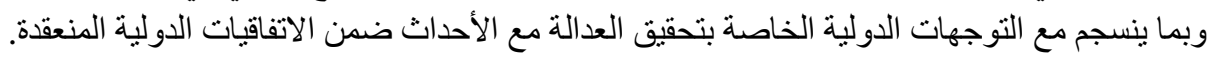

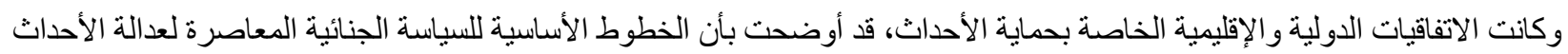

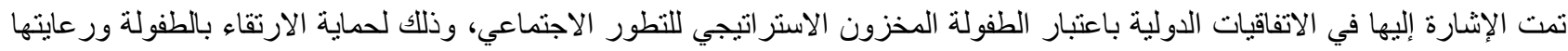

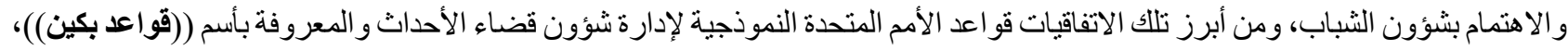

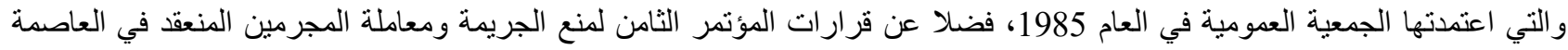

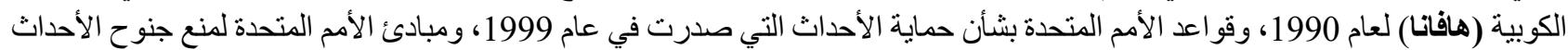

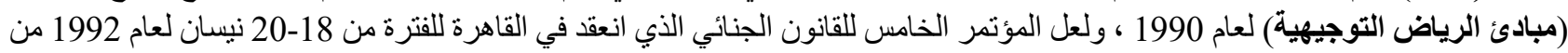

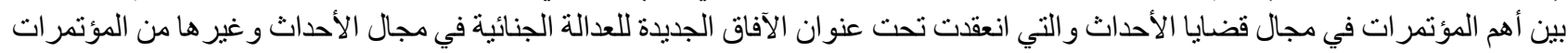

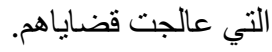

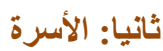

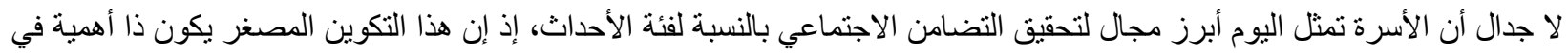

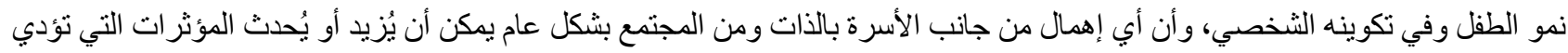

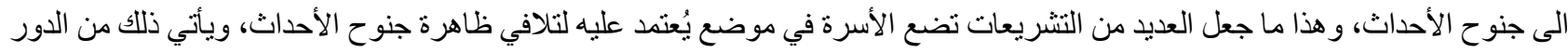
الوقائي الذي تمارسه الأسرة في ضوء القات القوانين و السياسات التي تضعها الدول.

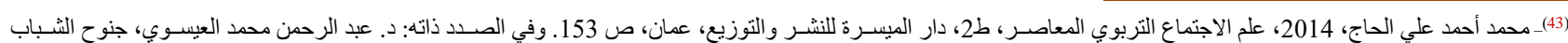

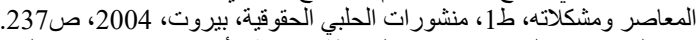

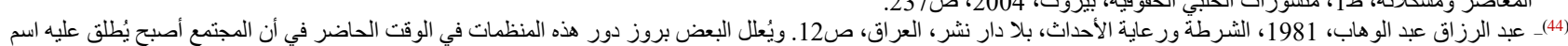

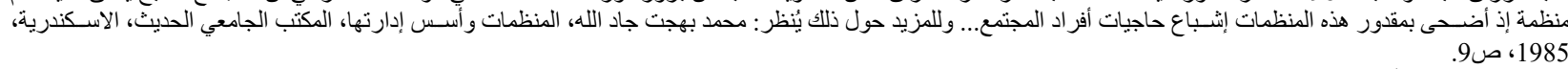
(45)- زيدان فاطمة شحاتة أحمد، 2004، مركز الطفل في القانون الدولي العام، دار الخدمات الجامعية، مصر، ص 407 ـ 408. 
لذلك فإن الحدث في مرحلة الطفولة المبكرة لا يكون خاضعاً لتأثثر جماعة أخرى غير أسرته وهو في ذللك يكون شديد الحساسية سهل التأثير

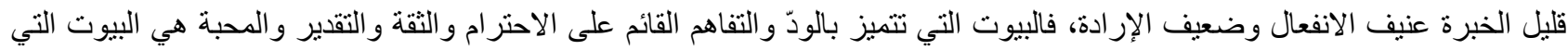

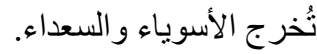

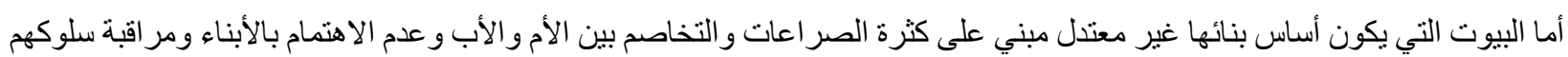

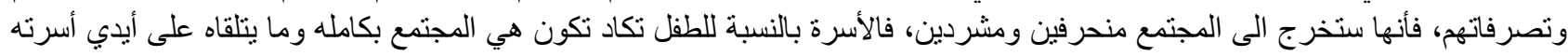

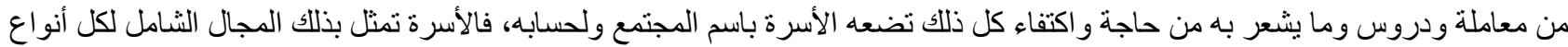

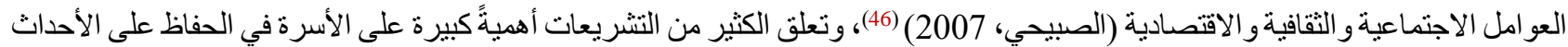

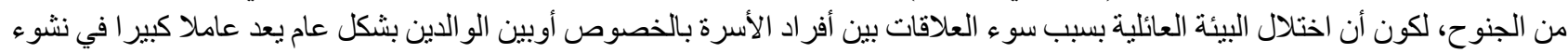

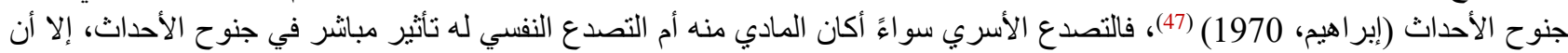

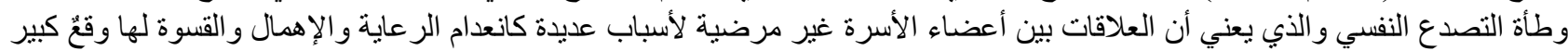
في نفسية الحدث و التي تؤدي به نحو الجنوح ( حمودة، 2008) (48).

و هذا ما حدى بالأمم المتحدة الى أن تسجل في ديباجة اتفاقية الطفل سنة 1979، إذ ألقيت في افتتاحية هذه الاتفاقية و التي تعتبر بمثابة ميثاق

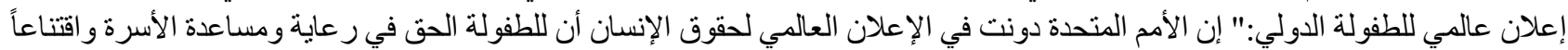

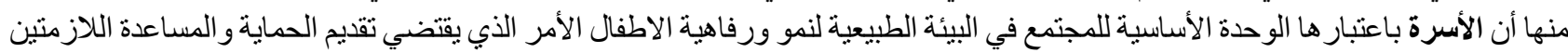

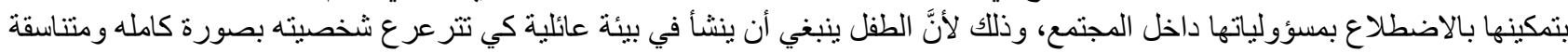

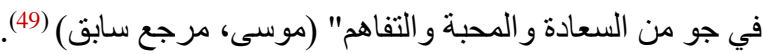

المبحث الثاني

\section{الوسنائل الكهئة بإعادة تأهيل العدث الجاتح}

لا تقتصر آثار التضامن الاجتماعي الخاصة بالحدث الجانح على إعادة تكييفه اجتماعيا، بل تمند لتشمل إعادة تأهيله للتأقلم مع أفراد مجتمعه

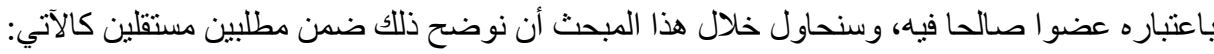

المطلب الأول

\section{التصنيف و الاسنثقبال و الثبر امج الصحية.}

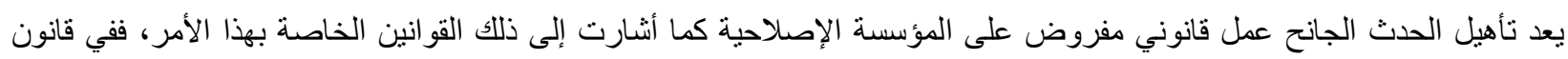

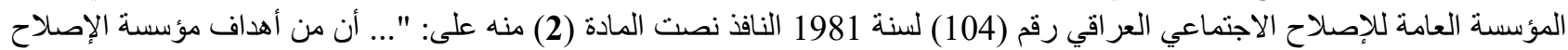

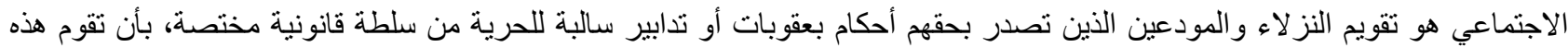
المؤسسة بتصنيفهم وتأهيلهم سلوكياً وتربويا ومهنيا".

فمن هذا النص يتضح أن المشرع العر اقي قد أدخل النظرة الحديثة الخاصة في عمل المؤسسة العقابية ودور ها في تأهيل المحكوم عليه من إندا

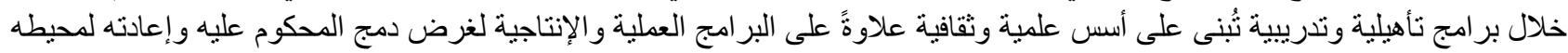

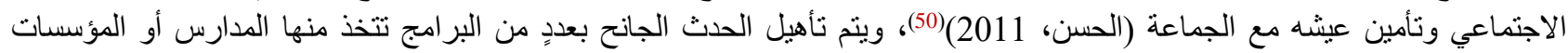
الإصلاحية منهجا لها للتعامل مع الحدث، ومن هذه البر امج نذكر منها ما يأتي:

الثرع الأول

برامج التصنيف والاستقبال

لا غلو في القول إن هذا البرنامج يعد أهم برامج التأهيل للأحداث الجانحين وهو على قدر كبير من الأهمية في تطبيق العملية الإصلاحية،

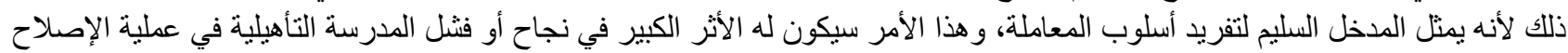

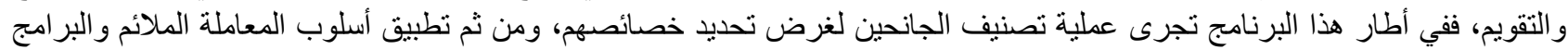
العلمية لحاجاتهم المختلفة، وبما يؤدي إلى تحقيق الأهداف التأهيلية، فالتصنيف إذن من وسائل تفرئ تفريد العقاب.

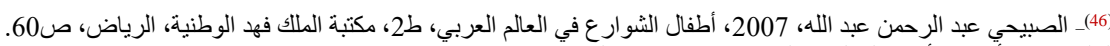

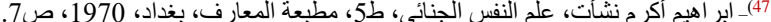

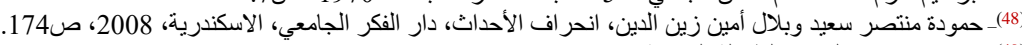

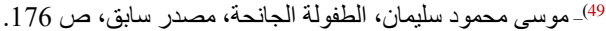

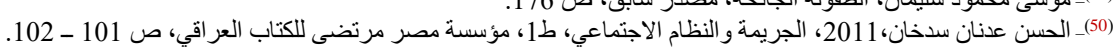




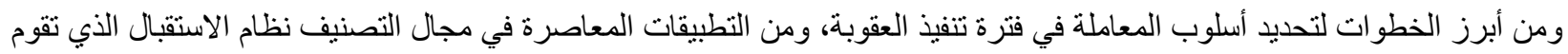

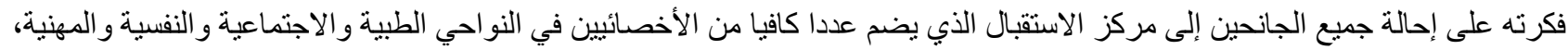

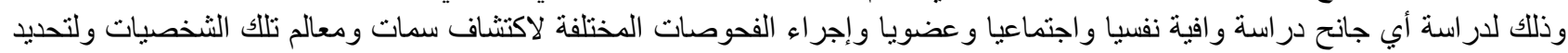

العو امل التي تقود إلى عدم تآلفهم الاجتماعي و الأسباب التي تباعد بينهم وبين قيم التهب المجتمع (قاسم، 1988) (51).

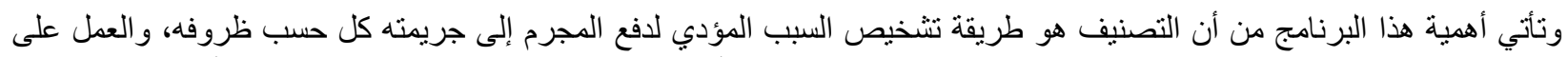

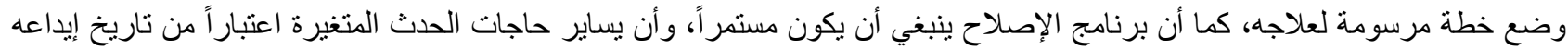

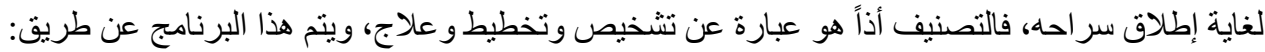

1- در اسة وتحليل حالة كل محجوز باستعمال شتى الطرق العلمية و الفنية منها كالتحريات الاجتماعية للمدان و الدراسات الطبية و العقلية

و الاختبار ات النفسية.

2- در اسة قابليات المدان الثقافية و المهنية ودر اسة معتقداته الدينية ومدى ايمانه وتقبله للأمور الدينية.

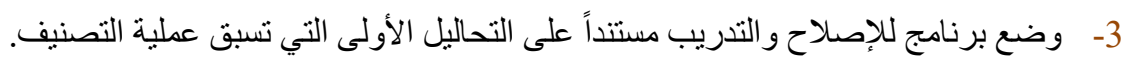

4- وضع هذا البرنامج في حيز التنفيذ و الإشر اف عليه بصورة مستمرة.

5- مر اقبة تطور ات المدان الناتجة عن تطبيق البرنامج ومحاولة تغييره إذا ما اقتضى الأمر ذلك.

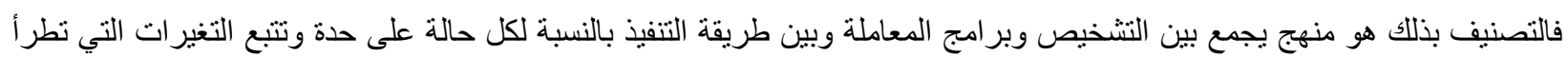

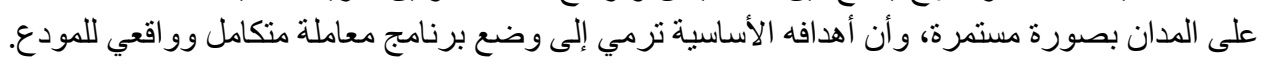

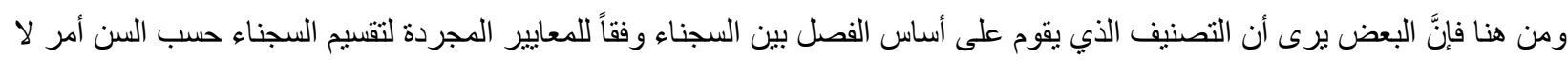

علاقة له بالتصنيف العلمي الذي يقتضي الجمع بين التتخيص وبر امج المعاملة وبين طريقة التنفيذ بالنسبة لكل حالة على حدة (عبد الوهاب،

الفرع الثاني

البرنامج الصحي

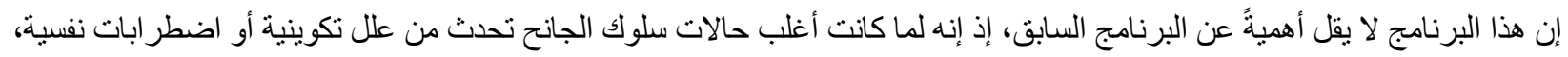

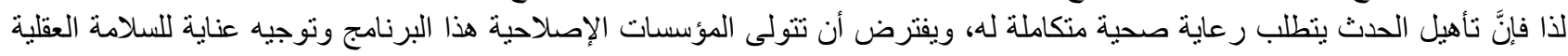

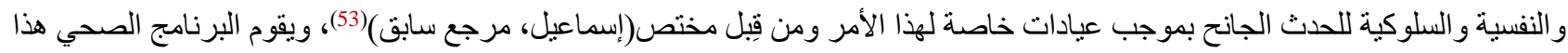

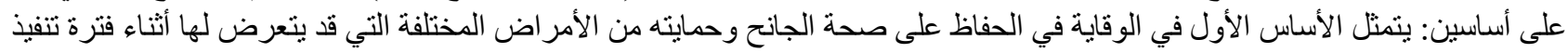

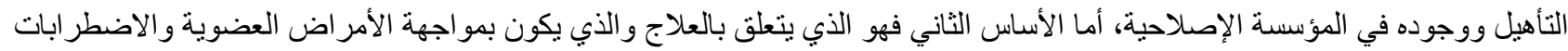

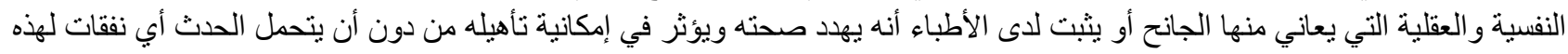

المعالجة (قاسم، مرجع سابق) (54).

المطلب الثَاني

البرنامج التُطليمي و العمل و التّريب

إن للتعليم و التنديب للحدث الجانح دور أسساسي ومهم في إعادة نوظيف قدر اته النفسية و العقلية في نوع التعليم أو العمل الذي يجد شخصيته

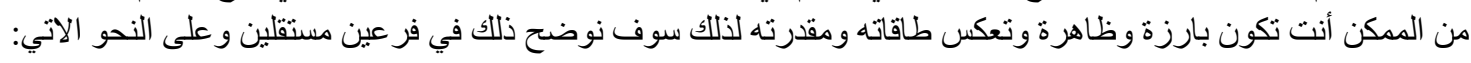

الفرع الأول

البرنامج التعليمي

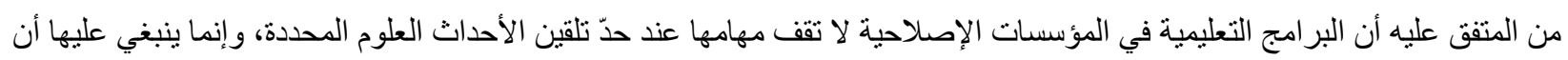

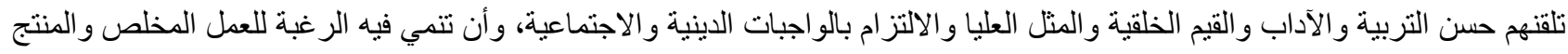

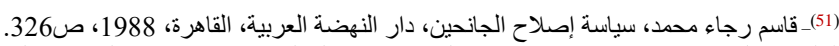

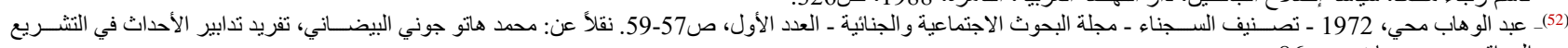

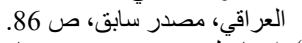

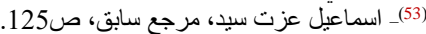

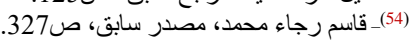


و المنافسة المشرو عة مع أقر انه، وذللك لأنَّ الحصول على الثهادة المدرسية بعد الاختبارات التي اجتاز ها بالعلوم المحددة التي نالها مهما كانت قيمتها العلمية قد تجعل صناحبها وبالاً على نفسه و على المجتمع الذي يعيش فيه (الحسيني، مرجع سابق) (55).

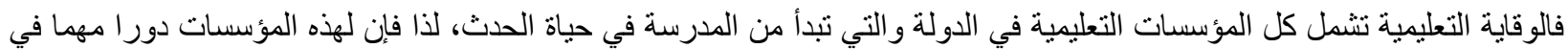

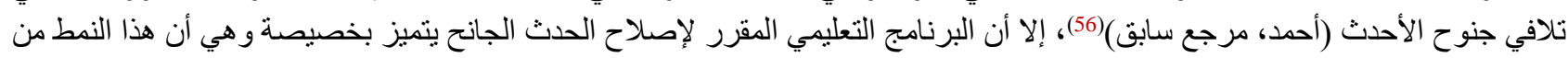

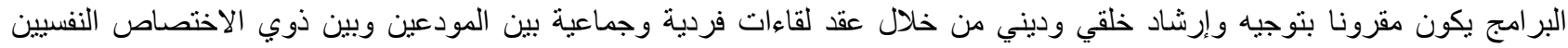

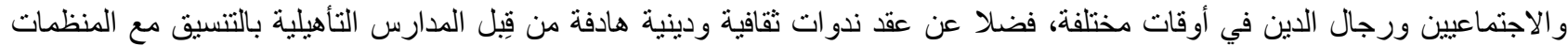

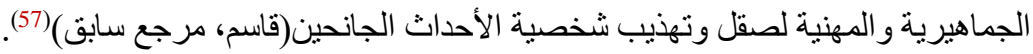

الفرع الثاني برامج العمل والتدريب

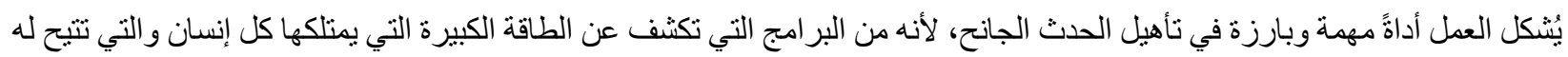

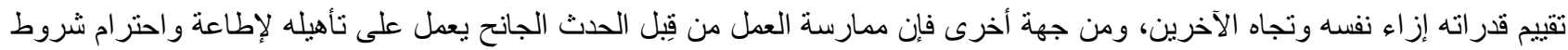

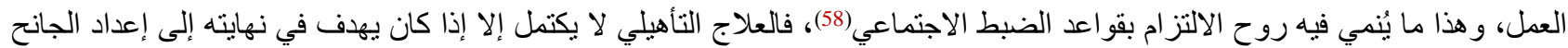

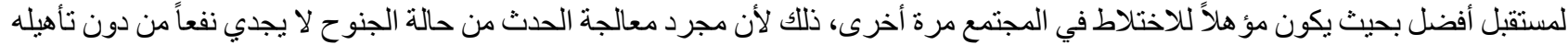

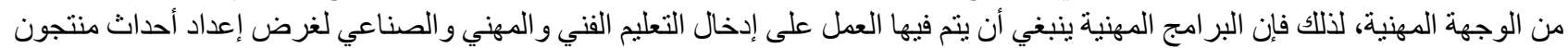
في نهاية تطبيق هذه البر امج ( الدباغ، ) (59).

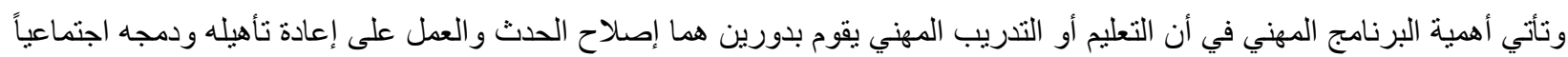

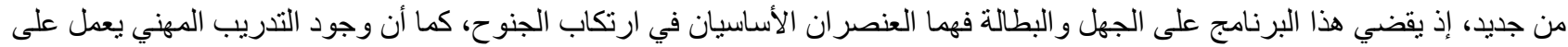
منع الأحداث من الجنوح مرة أخرى في الأحوال التي يكون فيها سبب جنوحهم يعود إلى الفاقة أو الحاجة المادية (العبيدي، مرجع سابق)(60).

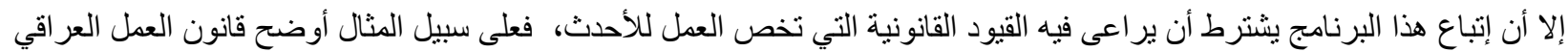

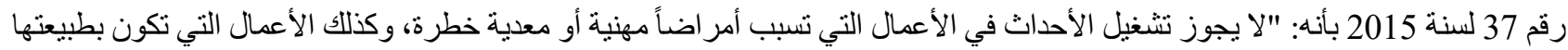

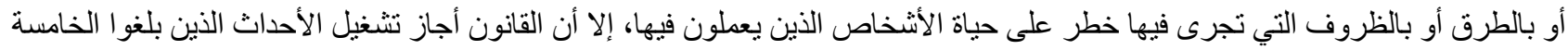

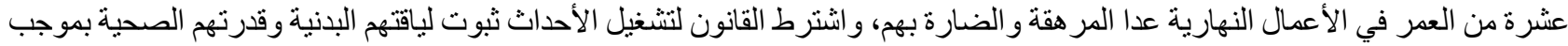
شهادة طبية صادرة عن جهة مختصة " وفقا لأحكام المادتين المادة (90، 91) من قانون العمل العر اقي النافذ.

الخاتمهة

استهدفت هذه الدراسة التعرف على مضمون التضامن الاجتماعي في قانون رعاية الأحداث العر اقي، وفي بعض من القو انين التي تناولت بالاهتمام مسألة رعاية الحدث الجانح، وفي ذلك توصلنا الى مجمو عة من الاستنتاجات و المقترحات و التي سنتناولها لألها على النحو الآتي:

أولا: الاسنتنتاجات

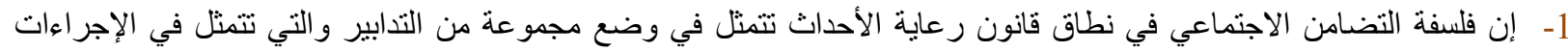

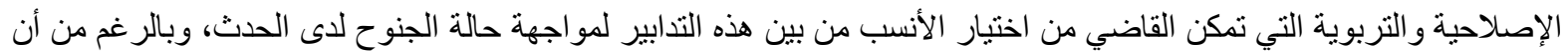

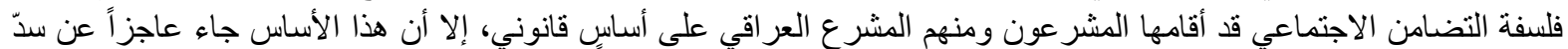

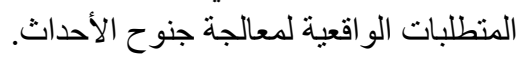

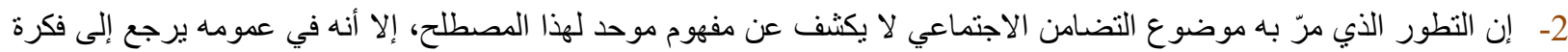

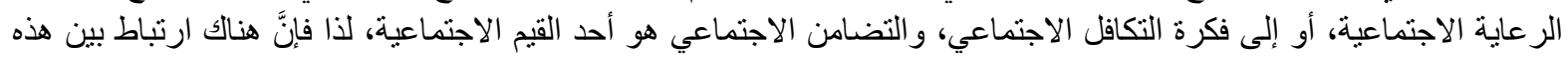

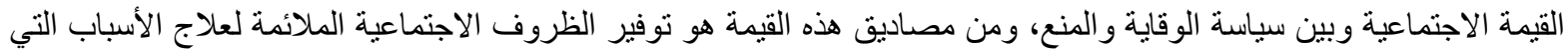

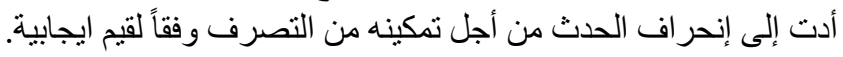

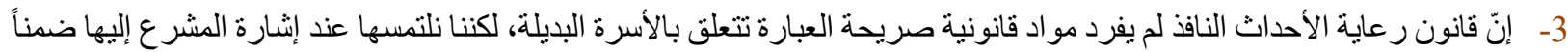

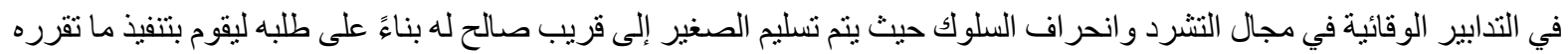
المحكمة من توصيات في ضوء تقير تقرير مكتب در اسة الثخصية. 


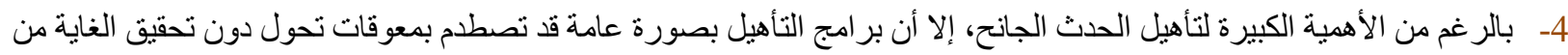

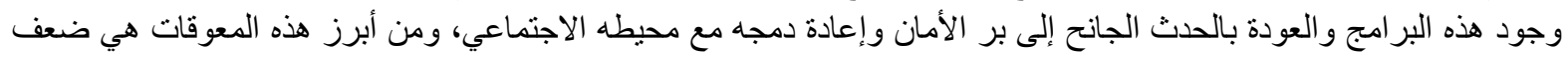

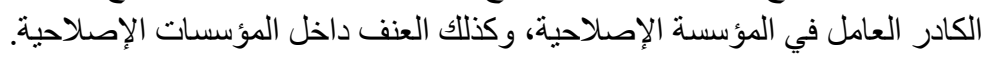

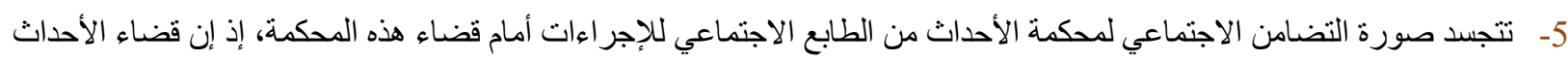
هو قضاء من نوع خاص يجمع بين طياته الصفة الجز ائية و الصفة الصناعة الرعائية. ثُانيا: المقترحات

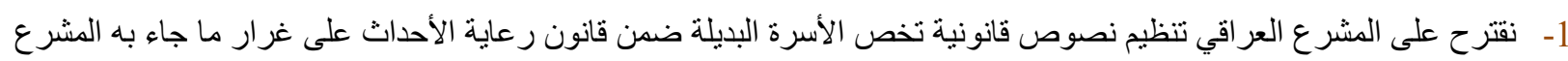
المصري في المادة (87) من اللائحة التنفيذية لقانون الطفل المصري و المعدية المدلة بالقرار رقم 178 لسنة 2016.

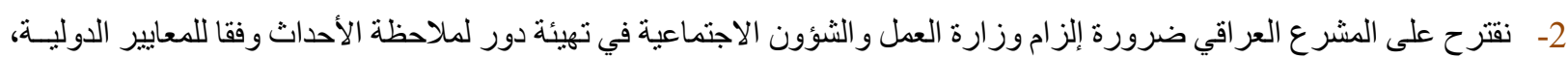

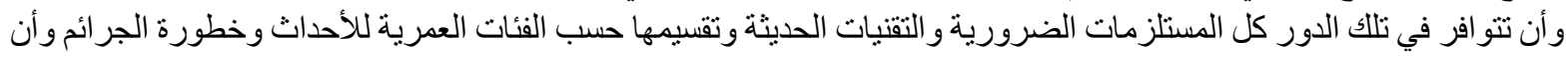
يكون الإشر اف عليها من قبل كادر متخصص.

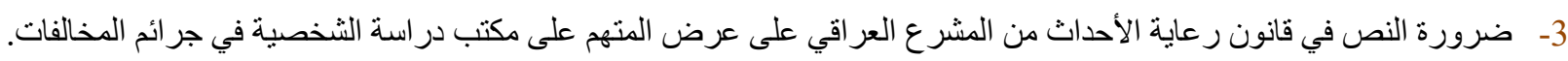

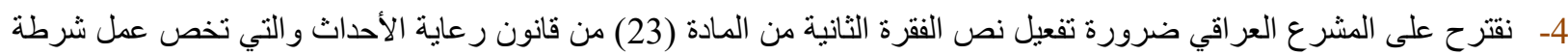

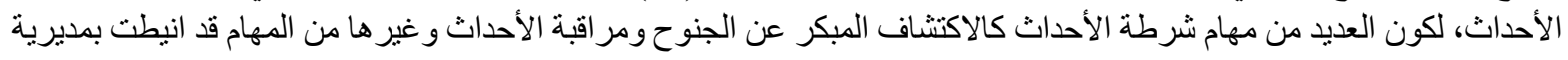
الثرطة السياحية.

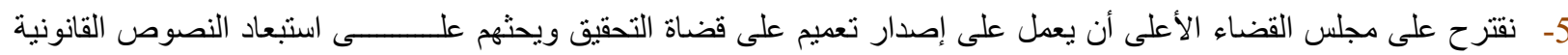

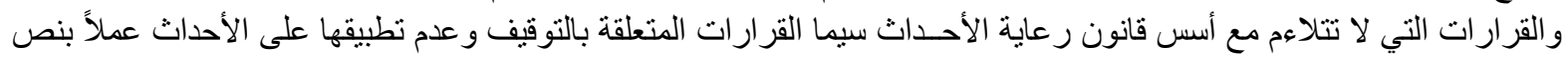

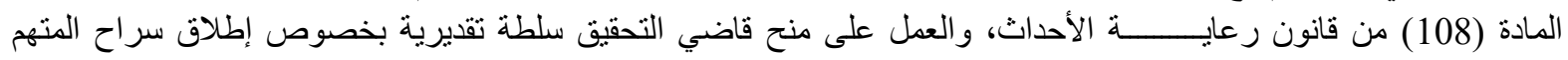

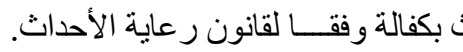

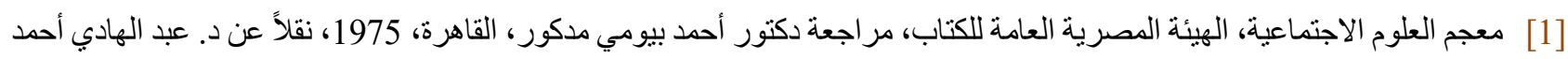

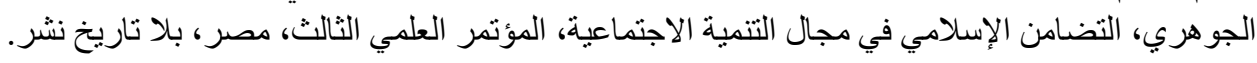

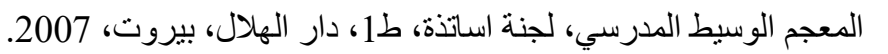

$$
\text { ثُانيا: الكثب القانونية }
$$

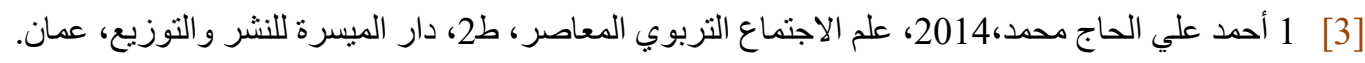

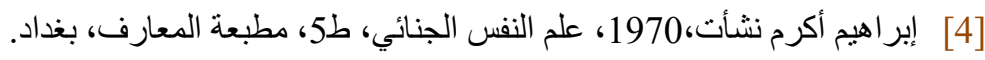

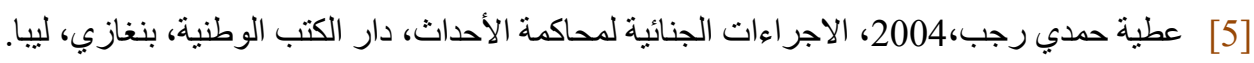
[6] الياسين جعفر عبد الأمبر،1994، شرطة الأحداث في العراق، مطبعة بابل، بغداد.

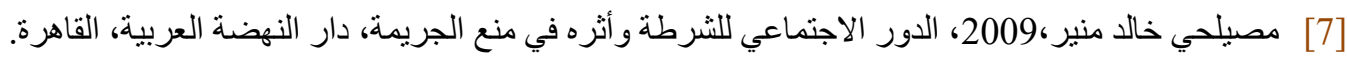

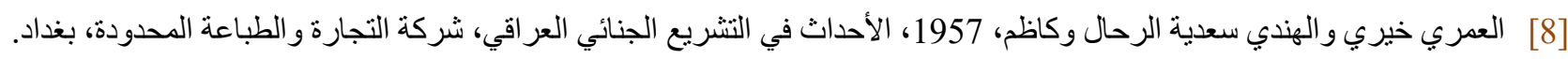

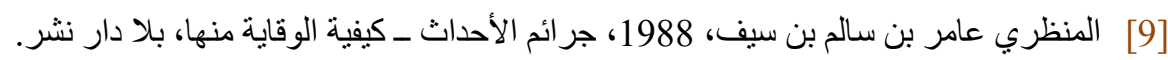

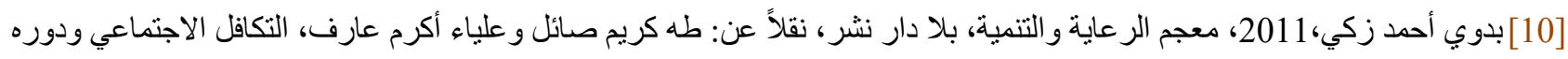

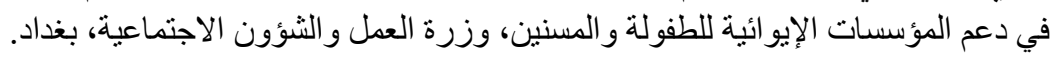

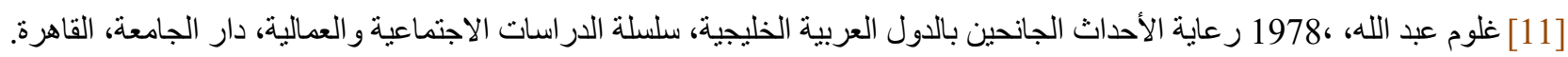

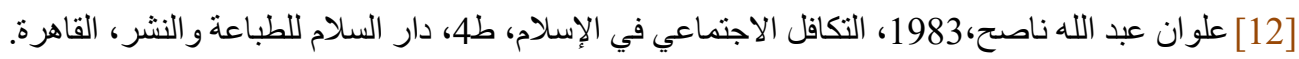

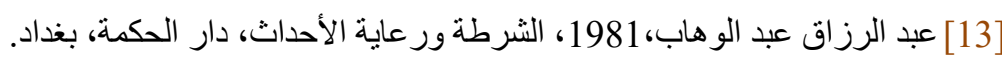

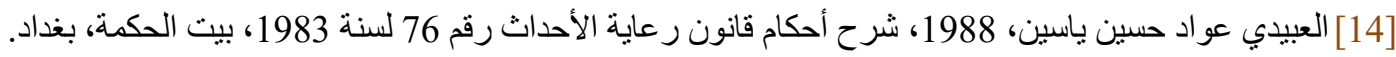

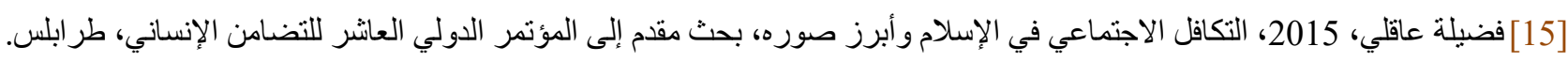

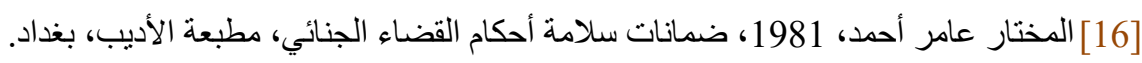
[17] الحسيني عباس وحمودي الجاسم، 1976، الأحداث الجانحون في علم الفقه و القضاء، مطبعة الإرشاد، بغداد. 
[18] شمس الدين عبد الأمير،2001، التربية بين الور اثة و البيئة، دار البلاغة للطباعة والنشر، بيروت.

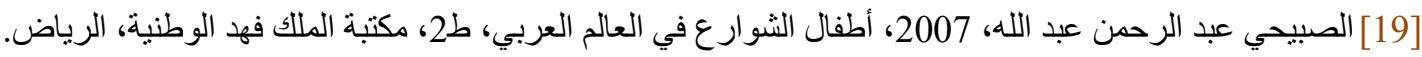
[20] العيسوي عبد الرحمن محمد،2004، جنوح الثباب المعاصر ومشكلاته، ط1، منشور ات الحلبي الحقوقية، بيروت. [21] حجازي عبد الفتاح بيومي،2007، المعاملة الجنائية والاجتماعية للأطفال، دار الكتب القانونية، مصر.

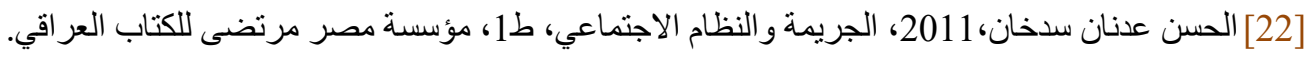
[23] اسماعيل عزت سيد،1984، جنوح الأحداث، ط1، وكالة المطبوعات، الكويت. [24] يوسف عصام، 2006التوجيه التربوي و الإرشاد النفسي، دار أسامة للطباعة، الأردن.

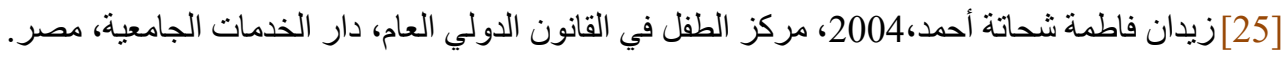

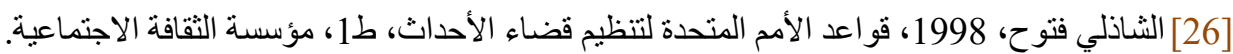
]27] الزبيدي كامل علوان،2010، 2010، علم النفس الجنائي، ط1، دار الور القاق للنشر و التوزيع، الأردن.

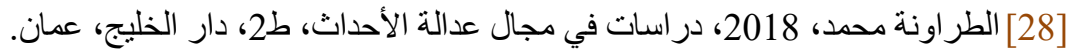
[29] عبد السلام محمد عوض،1986، الفعل الاجتماعي عند تالكوت بارسونز ، منشور ات جامعة الاسكندرية، مصر. [30] موسى محمود سليمان،2006، قانون الطفولة الجانحة و المعاملة الجنائية للأحداث، منشأة المعارف، الاسكندرية.

[31] حمودة منتصر سعيد وبلال أمين زين الدين، 2008، انحر اف الأحداث، دار الفكر الجامعي، الاسكندرية. [32] يعقوب مجد الدين محمد بن،1987، القاموس المحيط، بلا ط، دار الكتب العلمية، بيروت. [33] [أحد مجدي عبد الكريم،2009، جر ائم الأحداث وطرق معالجتها، دار الجامعة الجديدة، الاسكندرية. [34] ابو زهرة محمد،1970، المجتمع الإسلامي، دار الفكر العربي، القاهرة.

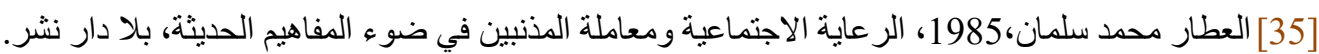

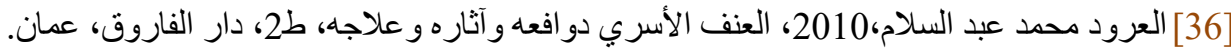
[37] التكريتي منذر كمال عبد اللطيف، 1978، السياسة الجنائية في قانون العقوبات العر اقي، ط1، دارة دار الرسالة للطباعة، بغداد. [38] صالح موفق محمد، 2010، دراسة حول أطفال الثوارع في العراق، وزارة العمل و الثؤون الاجتماعية، العراق. [39] العبيدي نبيل، 1999، أسس السياسة العقابية في السجون ومدى التزام الدولة بالمو اثيق الدولية.

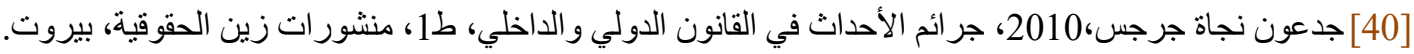
[41] أحمد هلالي عبد اللاه، 2006، حقوق الطفولة في الثريعة الإسلامية، دار النهضة العربية، القاهرة. ثالثا: المجلات الدورية

[42] عنوز أمل فاضل عبد خشان، 2015، الأمن السياحي ومدى فاعليته للحدّ من الجريمة السياحية، بحث منشور في مجلة كلية الحقوق ـ

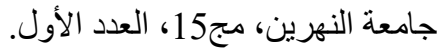

[43] يس السيد، 1998، مدخل للمشكلات الأساسية في علم الاجتماع القانوني، بحث منشور في مجلة الجناة القومية، العدد الخامس. [44] عبد الو هاب محي، 1972، تصنيف السجناء ـ مجلة البحوث الاجتماعية والجنائية ـ العدد الأول. [45] الأمين محمد صالح، 2007، آر اءو وملاحظات في قضاء الأحداث في العراق، بحث منشور في مجلة أهل البيت، العدد 5. رابعا: الرسائل الجامعية

[46] الطائي صبا محمد موسى، 2003، ضمانات المتهم الحدث في مرحلة المحاكمة، رسالة ماجستير، كلية القانون ـ جامعة الموصل. [47] قواسمية محمد عبد القادر، 1983، جنوح الأحداث في التشريع الجزائري، رسالة ماجستير، كلية القانون - جامعة بغداد.

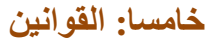

[48] قانون العقوبات الجز ائري رقم 156 لسنة 1966. [49] قانون الأحداث المصري رقم (31) لسنة 1974 [50] قانون الأحداث رقم 76 لعام 1983.

[51] قانون الإجر اءات الجنائية الجز ائري رقم 45 لسنة 1987 المعدل. [52] قانون الطفل المصري رقم 12 لسنة 1996و المعدل بالقانون رقم 26 لسنة 2008 


$$
\text { [53] قانون العمل العر اقي رقم } 37 \text { لسنة } 2015 .
$$

\title{
A BOOK
}

[54] HALL Pater, the political sources of social solidarity, Harvard library, 2017, p. (1)349.

[55] LAWRENCE WILDE, the concept of solidarity, Cambridge university, 2006, (4)p.1.

\section{RESEARCH ARTICLE \\ THE ROLE OF SOCIAL SOLIDARITY IN THE REHABILITATION OF JUVENILE DELINQUENT IN THE IRAQI JUVENILE WELFARE LA W}

\author{
Mazin Khalaf Naser \\ Dept. of Public law, College of Law, Al-Mustansiriya University, Iraq \\ *Corresponding author: Mazin Khalaf Naser; E-mail: dr.mazin67@uomustansiriyah.edu.iq
}

Received: 30 October 2021 / Accepted: 20 November 2021 / Published online: 31 December 2021

\section{Abstract}

Societies, especially the developed ones, aim to regulate juvenile or child care laws to ensure that the greatest amount of this care is achieved, and this care and attention to the juvenile or child cannot be achieved without guarantees, controls, future plans, and practical studies that show the flaws in performance and negatives, and diagnose the positives for the purpose of adopting them. And its development, which accompanies the process of care and coincides with the age of the juvenile or the subsequent after his delinquency, in order to return and rehabilitate him within the community, with the application of general principles of human rights and charters and agreements that govern the issues of children and juveniles. In reducing the possibilities of delinquency and criminality, and stipulating the responsibility of parents in the event that they neglect their duties towards the juvenile in a negligence that leads to delinquency and homelessness or delinquency, as well as the provision of special preventive measures that will work to rehabilitate them in a way that ensures their reintegration again among the community circles, and this result only comes According to the text of a legal system that is the necessity of obligating society to contribute to the reform of the juvenile through social solidarity among all members of society P. for the purpose of taking the hand of the juvenile towards the correct behavior, and working to treat the juvenile behavior spoiled by delinquency.

Social solidarity, despite being a term that carries with it various visions, differs from the preventive criminal policy followed in a particular country from another, but today it has become one of the agreed principles on the necessity of activating it and working to find it within the framework of the laws related to the care of juveniles.

Keywords: Juvenile, Prevention, Solidarity, Qualification, Deviation.

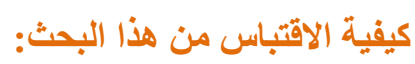

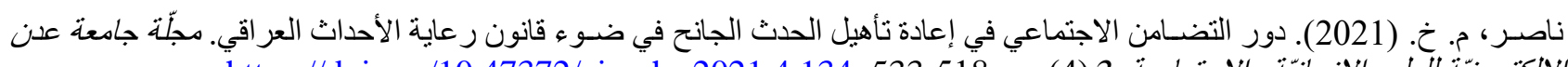

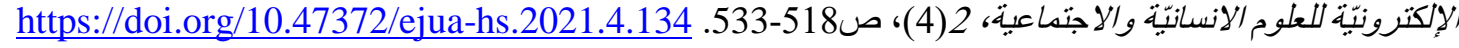

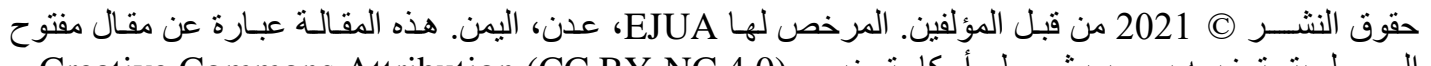

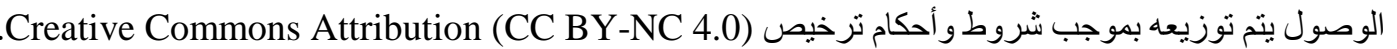

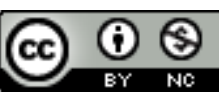

